\title{
Methodenvergleiche am Beispiel von "supersensitiven" TSH-Assays. Statistische und probabilistische Aspekte
}

\author{
H. Keller \\ Institut für Klinische Chemie und Hämatologie des Kantons St. Gallen
}

\begin{abstract}
Zusammenfassung:
Mit den neuen supersensitiven TSH-Assays können noch Thyrotropin-Konzentrationen $<0,1 \mathrm{mU} / \mathrm{l}$ bestimmt werden. Es stellt sich die Frage, ob mit dieser methodischen Verbesserung auch eine Steigerung der diagnostischen Validität der Kenngröße TSH erzielt wird. Die statistische Analyse eines Literaturbeispiels zeigt, daß beim Vergleich euthyreoter und hyperthyreoter Patienten die Zahl der falschen Zuordnungen mit den neuen Testkombinationen nicht signifikant reduziert wird; der Überlappungsbereich ist sogar bei dem neuen TSH-Assay größer.
\end{abstract}

Probabilistische Berechnungen, etwa der Likelihood-Quotienten und der entsprechenden LQ-Geraden ergeben jedoch, daß die diagnostische Trennfähigkeit der neuen TSH-Assays deutlich besser ist.

Zur Klärung der Frage, ob die Bestimmung der basalen TSH-Konzentration mit supersensitiven Assays den TRH-Test ersetzt, wurde das Referenzintervall der Kenngröße „basales TSH" ermittelt und zum Referenzintervall "TSH-Inkrement" (nach TRH-Stimulation) in Beziehung gesetzt. Es zeigte sich, daß sich die Histogramme von Patientenkollektiven mit eingeschränkter, normaler oder überschießender TSH-Antwort auf TRH-Stimulation in weiten Bereichen überdecken. Die Kenntnis des basalen TSH-Spiegels erlaubt demnach meist keine zuverlässige Voraussage über den Ausfall eines TRH-Tests, auch wenn der basale TSH-Spiegel mit einem supersensitiven Assay ermittelt.wurde.

\section{Schlüsse/wörter:}

Thyrotropin (TSH) - TRH-Test - supersensitiver TSH-Assay - $\chi^{2}$ - Overlap-Index - LikelihoodQuotient - diagnostische Validität

\section{Summary:}

With the new "supersensitive" assays for thyrotropin it is possible to determine concentrations below $0.1 \mathrm{mU} / \mathrm{l}$. The question arises, whether this methodological improvement also leads to an improvement of the diagnostic validity of the parameter TSH. A statistical analysis of an example in the literature shows that the discrimination between euthyroid and hyperthyroid patients is not improved. This means that the number of patients incorrectly allocated is not significantly reduced by the new test; the overlapping zone is even broader with the new TSH-assay.

Probabilistic calculations, e.g. on the basis of likelihood-quotients and corresponding LQ-lines show, however, that the diagnostic validity of the new TSH assay is significantly better.

To clarify the question, whether the determination of basal TSH concentrations with supersensitive assays replaces the TRH test, the reference interval of the parameter" basal TSH" was determined and correlated with the reference interval of "TSH-increment" (after TRH stimulation). As a result, the histograms of populations with reduced, normal or increased TSH response to TRH stimulation showed broad overlapping zones. Thus the ${ }^{-k}$ nowledge of the basal TSH rarely allows a reliable prediction of the result of a TRH test, even if the basal TSH was estimated with a supersensitive assay.

Keywords:

Thyrotropin (TSH) - TRH test - supersensitive TSH assay - $\chi^{2}$ - overlapping index - likelihoodquotient - diagnostic validity

\section{Problemstellung}

In jüngster Zeit wurden von verschiedenen Firmen „supersensitive" Testkombinationen zur Bestimmung von Thyrotropin (TSH) auf den Markt gebracht. Eine vergleichende Evaluation von sechs dieser Assays haben kürzlich Wood et al. (1) publiziert. Mit diesen neuartigen Immunoassays ist es möglich, TSH-Konzentrationen
$<0,1 \mathrm{mU} / \mathrm{l} \mathrm{zu}$ bestimmen. Deshalb bieten sich zwei wichtige neue Aspekte für die Șchilddrüsendiagnostik:

- Bei den früheren TSH-Assays endete der Meßbereich etwa bei $1 \mathrm{mU} / \mathrm{l}$. Da viele schilddrüsengesunde Personen aber niedrigere TSH-Konzentrationen im Blut aufweisen, war es nicht möglich, die untere Grenze des Referenzintervalls von euthyreoten Probanden zu definieren. Dank der „supersensitiven” Assays ist dies nun möglich. 
- Zugleich wird damit jener TSH-Konzentrationsbereich der Messung zugänglich, der bei hyperthyreoten Patienten zu erwarten ist.

Es stellt sich nun das bekannte Problem: Für die Bestimmung eines Parameters stehen zwei Methoden zur Verfügung, zu deren quantitativer Bewertung im Hinblick auf ihre diagnostische Validität statistische und/oder probabilistische Verfahren herangezogen werden können. Die Anwendung beider Betrachtungsweisen auf Evaluationsdaten führt jedoch nicht notwendigerweise zu identischen Schlußfolgerungen.

\section{Vergleich konventionelle vs supersensitive TSH-Assays}

\section{Auswertung der Studie Hermann et al. (2)}

Dies sei zunächst an einer kürzlich von Hermann et al. (2) publizierten vergleichenden Studie über den diagnostischen Wert von TSH-Assays exemplifiziert. Der Originalarbeit ist die Darstellung der Datenbasis entnommen (Abb. 1).

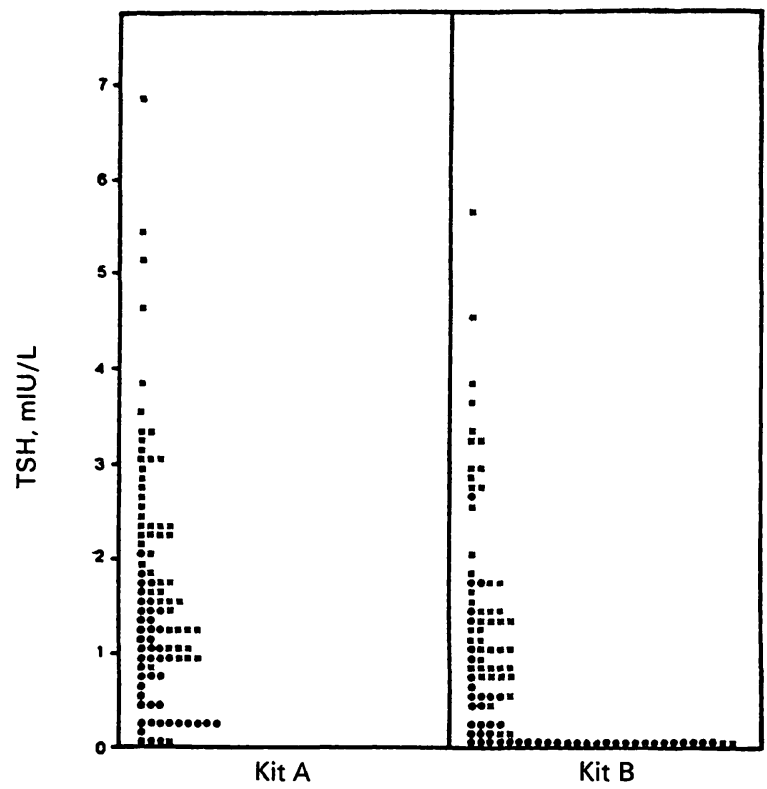

Abb. 1: Verteilung der basalen TSH-Konzentrationen bei euthyreoten (Kreis) und hyperthyreoten Patienten (Kreuz). Die Bestimmung erfolgte mit der Testkombination .Magic TSH Corning" alte Version (A) und neue Version (B) [aus (2)]

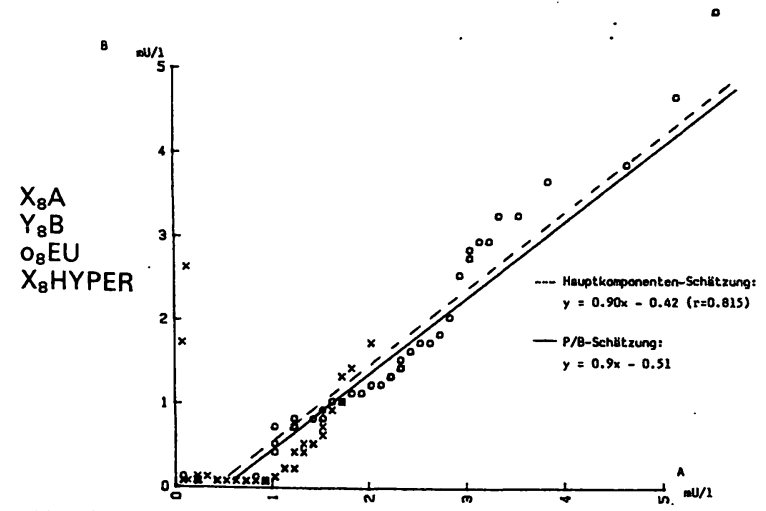

Abb. 2: Wie Abb. 1, jedoch als $x / y$-Diagramm dargestellt
Es handelt sich um eine Population von euthyreoten und hyperthyreoten Patienten. Der thyreotoxische Zustand galt als gesichert, wenn entsprechend veränderte Konzentrationen von total T4, FT4 und T3 gefunden worden waren. Hypothyreote und unklare Fälle wurden nicht in die Population aufgenommen. Die Bestimmung des TSH erfolgte mit der Testkombination "Magic-TSH", Corning, alte Version (A) und neue Version (B).

\section{Statistische Verfahren: Korrelation und Regression}

Transformation der originalen Abbildung in eine $x / y$-Graphik ergibt Abb.2, wobei die alte Methode auf der $x$-Achse, die neue auf der $y$-Achse skaliert ist. Die Wertpaare der Euthyreoten sind als Kreis, die der Hyperthyreoten als Kreuz symbolisiert. Offensichtlich besteht eine Abhängigkeit zwischen Test $A$ und $B$, doch ist die Annahme eines linearen Zusammenhangs kaum zulässig. Eher ist anzunehmen, daß die Antikörper von Test $A$ andere antigene Determinanten auf dem Glycoprotein TSH erkennen als die Antikörper von Test B. In diesem Zusam-

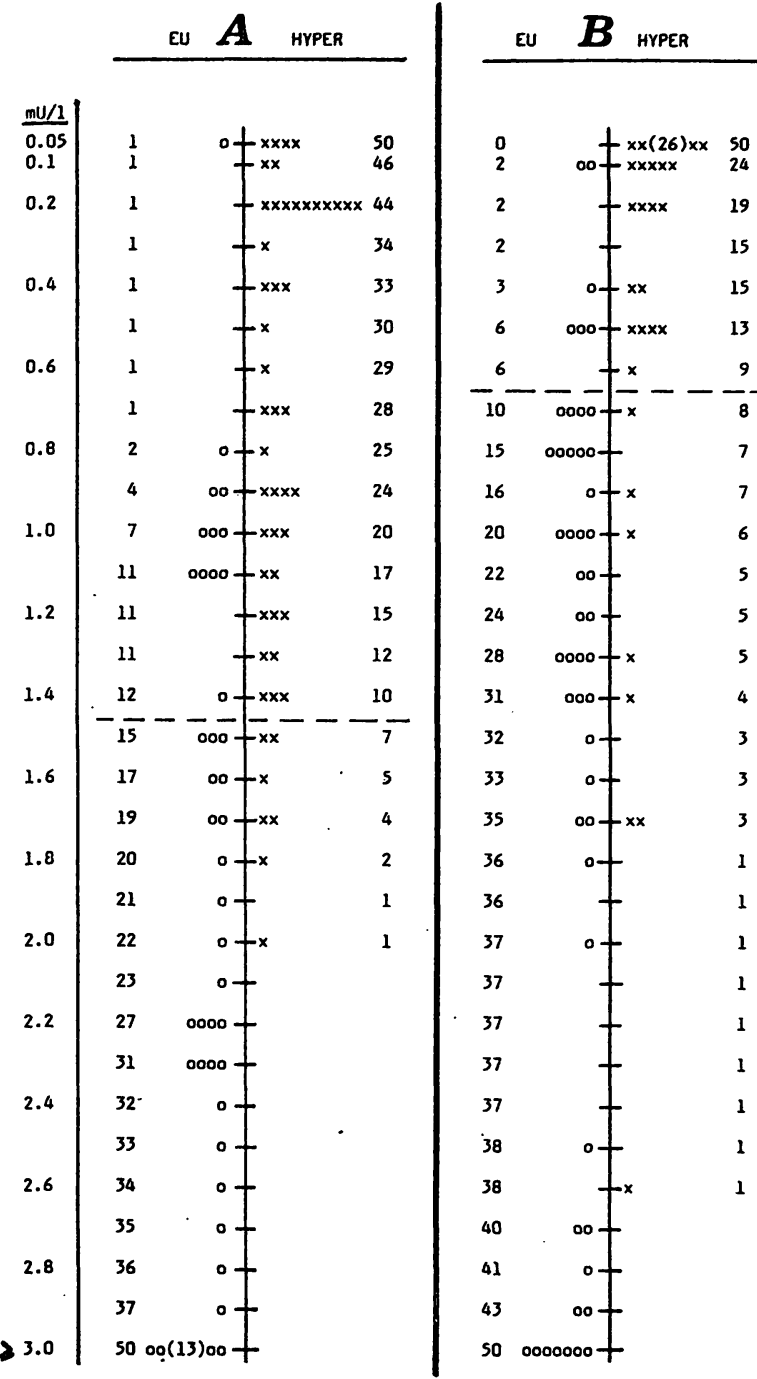

Abb. 3: Die Daten aus Abb. 1 sind als Stabdiagramm aufgezeichnet. Die Euthyreoten (Kreis) jeweils links, die Hyperthyreoten (Kreuz) jeweils rechts des Stabdiagramms. Links neben dem Stabdiagramm sind die euthyreoten von oben nach unten kumuliert, rechts die hyperthyreoten Patienten von unten nach oben. Die äußerste linke Kolonne gibt die TSH-Konzentrationen wieder. 
'menhang sei daran erinnert, daß Thyrotropin aus zwei Peptidketten zusammengesetzt ist und daß seine $\alpha$-Kette mit den $\alpha$-Ketten verschiedener Gonadotropine identisch ist.

Werden die vorhandenen 100 Wertpaare einer PassingBablok-Schätzung (3), resp. einer HauptkomponentenSchätzung unterzogen $(4,5)$, so zeigt sich, daß beide Verfahren den Achsenabschnitt relativ ähnlich schätzen, auç die Steigung stimmt fast völlig überein. Die Verteilungen von $A$ und $B$ sind jedoch nicht normal und der girlandenartige Verlauf um die Ausgleichsgerade spricht gegen eine lineare Regression beider Assays.

\section{Ermittlung der optimalen Entscheidungs-Schwelle}

Deshalb wurde eine andere Art der Darstellung gewählt (Abb. 3). In der ersten Kolonne sind die Dimensionen für Test $A$ und $B$ einheitlich skaliert, zwei Stabdiagramme geben die Resultate beider. Tests wieder. Die Euthyreoten sind als Kreis jeweils nach links, die Hyperthyreoten als Kreuz jeweils nach rechts eingetragen. Die Zahl der Euthyreoten ist jeweils links vom Stabdiagramm von oben nach unten kumuliert, die Zahl der Hyperthyreoten jeweils rechts vom Stabdiagramm von unten nach oben kumuliert wiedergegeben. Da es sich lediglich um die Unterscheidung euthyreot vs hyperthyreot handelt, endigt die Werteskala bei $3 \mathrm{mU} / \mathrm{I}$.

Die erste Aufgabe besteht nun darin, festzulegen, an welcher Stelle der Skalen der optimale Entscheidungspunkt liegt, d.h. jene Grenze, bei der die größte Zahl richtiger und die kleinste Zahl falscher Zuordnungen bei Test $A$, resp. B, resultiert. Dank der kumulierten Reihung ist dieser Punkt leicht feststellbar: Wird das Stabdiagramm so geteilt, daß vier Felder entstehen, so gibt das linke obere Feld die Zahl der falsch-positiven, das rechte untere Feld die Zahl der falsch-negativen wieder. In Abb. 3 sind die

Tab. 1: $\chi^{2}$-Test zur Überprüfung der Frage, ob Test A Resultate liefert, die signifikant unterschiedlich von Test $B$ sind. Der Unterschied von 19 Falschen bei Test $A$ im Vergleich zu 14 Falschen bei Test B ist im $\chi^{2}$-Test nicht signifikant. Erst wenn Test $B$ nur 9 falsche Resultate (oder weniger) liefern würde, wäre eine signifikante Differenz auf dem 95\% Niveau gegeben
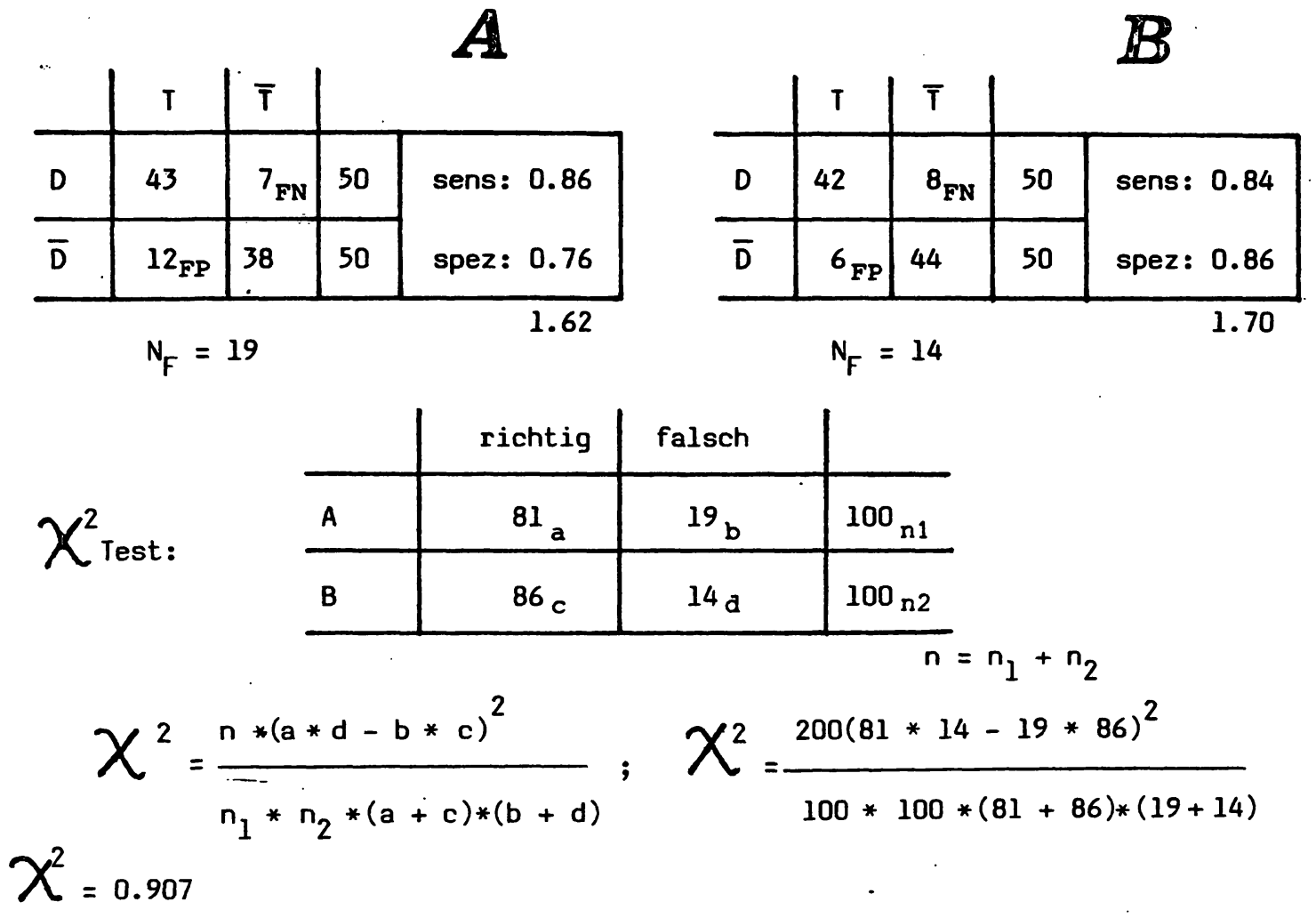

$$
\begin{aligned}
& X^{2} \ll X_{1 ; 0.01}^{2}=6.635 \\
& X^{2}<X_{1 ; 0.05}^{2}=3.841
\end{aligned}
$$

$$
\begin{aligned}
& \frac{\text { angenommen: }}{N_{F_{B}}=10 \rightarrow X^{2}=3.267} \\
& N_{F_{B}}=9 \rightarrow X^{2}=4.153 \\
& N_{F_{B}}=5 \rightarrow X^{2}=9.280
\end{aligned}
$$

ergo: Methode B nsd A 
optimalen Schwellen eingetragen: Für den Test A liegt die Grenze zwischen 1,4 und 1,5 $\mathrm{mU} / \mathrm{l}$, wobei die Zahl der falsch-positiven zwölf und die der falsch-negativen sieben beträgt. Für Test $B$ werden sechs falsch-positive und acht falsch-negative ermittelt, wenn die Grenze zwischen 0,6 und 0,5 mU// gesetzt wird. Mit anderen Worten, von 100 Patienten werden mit dem Test $A$ neunzehn, mit dem Test $B$ dagegen nur vierzehn falsch klassiert. Rechtfertigt dieser Unterschied den Wechsel von Test A zu Test B?

\section{Prüfungen der Signifikanz der Differenz}

\section{$\gamma^{2}-$ Test}

Zur Beantwortung dieser Frage stellt uns die schließende Statistik parameterfreie Signifikanz-Tests zur Verfügung. Zum Vergleich zweier relativer Häufigkeiten ist. z. B. der Einsatz eines 4 -Felder- $\chi^{2}$-Tests seit langem etabliert (siehe z. B. 6) (Tab. 1). Die Voraussetzungen zum Einsatz dieses Berechnungsverfahrens sind gegeben. Es errechnet sich ein $\chi^{2}$ von 0,907 . Wird eine Irrtumswahrscheinlichkeit von $\alpha=0,01$ vorgegeben, so beträgt die Signifikanzschranke 6,635 ; bei $\alpha=0,05$ immer noch 3,841 . Dies bedeutet, daß der Unterschied von neunzehn falschen im Vergleich zu vierzehn falschen Zuordnungen bei dieser Betrachtung als nicht signifikant zu beurteilen ist. Selbst wenn ein hypothetischer Test nur zehn Falsche geliefert hätte, gälte die Differenz noch nicht als signifikant. Erst bei neun Falschen (und weniger) wird die Irrtumswahrscheinlichkeit von 0,05 unterschritten.

Hermann et al. (2) finden jedoch mit einer sehr komplexen ROC-Analyse, daß der Test B eine kleine, aber signifikante Überlegenheit gegenüber Test $A$ besitzt. Wir haben deshalb noch ein weiteres neues statistisches Verfahren eingesetzt.

\section{Overlap-Index}

Um die Nützlichkeit diagnostischer Tests miteinander zu vergleichen, wurde unlängst der "Overlap-Index" empfohlen (Tab. 2) (7). Es handelt sich dabei um einen nichtparametrischen Index, der auf Rangsummen basiert und als Modifikation des Wilcoxon-Rangsummen-Tests aufgefaßt werden kann. Um den Overlap-Index eines Tests zu berechnen, werden zunächst alle Meßwerte einer Population - hier also die Meßwerte der euthyreoten und hyperthyreoten Patienten in aufsteigender Reihenfolge sortiert. Jedem Wert wird nun der entsprechende Rang zugeordnet; bei verbundenen Werten, d.h. Ergebnissen von gleichem numerischen Wert, wird der entsprechende Mittelwert des Ranges eingesetzt. Nun werden die Ränge eines Kollektivs, also z.B. der Euthyreoten, summiert und die spezifische Rangsumme erhalten. Zur Berechnung des Overlap-Index wird davon die mittlere Rangsumme abgezogen, die Differenz mit 2 multipliziert und durch das Produkt der beiden Kollektive geteilt. Die Resultante wird unabhängig vom Vorzeicherı von 1 abgezogen und so der Overlap-Index erhalten. Sein Wert beträgt 0 , wenn keine Überlappung zwischen beiden Kollektiven besteht und er beträgt 1,0, wenn beide Kollektive denselben Median haben.

Angewandt auf das Modell Hermann ergibt sich, daß für den alten Test $A$ der Overlap-Index 0,216 beträgt, für den neuen Test $B$ jedoch 0,237. Dieses überraschende Ergebnis besagt, daß sich beim neuen Test die beiden Kollektive mehr überlappen als beim alten. (Eine Kontrolle von Abb. 3 bestätigt dies: bei Test $A$ erstreckt sich das Überlappungsintervall von $0,8-2,0 \mathrm{mU} / \mathrm{l}$, umfaßt also $1,2 \mathrm{mU} / \mathrm{l}$; bei Test $B$ dagegen von $0,1-1,7 \mathrm{mU} / \mathrm{l}$, umfaßt also 1,6 $\mathrm{mU} / \mathrm{l}$ !)

Tab. 2: Berechnung des Overlap-Index nach Hartz (7). Die Breite des Überlappungs-Bereichs ist beim Test A kleiner als beim Test B (näheres siehe Text).

\section{Berechne:}

a) mittlere Rangsumme

b) spezifische Rangsumme $T=\sum_{1}^{N}$

c) over lap Index

$$
\bar{T}=N_{1} * \frac{N_{1}+N_{2}+1}{2}
$$

$$
O I=|-| \frac{2(T-\bar{T})}{N_{1} * N_{2}} \mid
$$

Modell Hermann

$\begin{array}{ll}\text { Test } A: & { }^{O I_{A}}=0.2164 \\ \text { Test B: } & O_{B}=0.2376\end{array}$ 


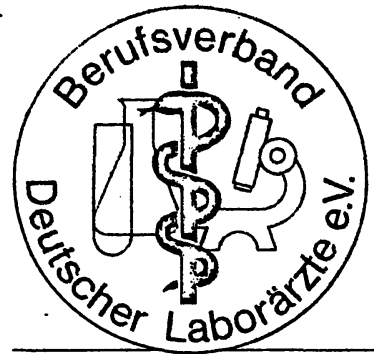

\section{Zur Strafbarkeit von „AIDS-Tests“ ohne ausdrückliche Einwilligung der Patienten}

Manfred Bruns

In der Praxis trifft man immer wieder auf die Meinung, der Arzt brauche seine Patienten nicht ausdrücklich um Einwilligung zu fragen, wenn er die ihnen zu Untersuchungszwecken abgenommene Blutprobe zusätzlich auf AIDS testen lassen will. Man ist offenbar der Auffassung, die allgemeine Zustimmung der Patienten zur Untersuchung und zur Blutentnahme decke auch den zusätzlichen „AIDS-Test” mit ab. Das erscheint bedenklich. Zwar gibt es sicher Routineuntersuchungen wie etwa Blutsenkungen, die ohne zusätzliche ausdrückliche Einwilligung der Patienten vorgenommen werden dürfen. Aber der "AlDS-Test“ ist mit solchen Routineuntersuchungen nicht vergleichbar.

Mit AIDS verhält es sich ähnlich wie mit den Geschlechtskrankheiten. Sie sind mit dem Odium des Unanständigen und des Unmoralischen verbunden. Ein „ordentlicher Bürger“ zögert nicht selten, mit einer Lues oder einem Tripper zu seinem Hausarzt zu gehen und fährt stattdessen lieber in die nächste Großstadt, wo inn niemand kennt. Er bezahlt dann auch die Arztrechnungen lieber selbst, als sie über seine Krankenkasse oder gar über die Beihilfestelle seines Dienstherrn laufen zu lassen. Bei AIDS sind diese Ängste aber noch viel ausgeprägter und berechtigter. Wenn bekannt wird, daß sich jemand mit AIDS infiziert hat, ist er damit als Homosexueller oder doch zumindest als jemand abgestempelt, der ein sexuell ausschweifendes Leben geführt hat. Er muß außerdem mit hysterischen Angstreaktionen seiner Angehörigen, seiner Freunde und seiner. Mitbewohner sowie den massiven Schwierigkeiten an seinem Arbeitsplatz rechnen. Leider hat sich ja noch immer nicht genügend herumgesprochen, daß AIDS im allgemeinen sozialen Umgang nicht ansteckend ist. Gesundheitsministerin Süßmuth hat zum Jahreswechsel mit Recht darauf hingewiesen, daß „keine Krankheit so bedrohlich und zugleich so vermeidbar ist wie AIDS". Mit AIDS kann man sich - von einigen hier nicht interessierenden Sonderfällen abgesehen - nur infizieren, wenn man bei sexuellen Abenteuern kein Kondom oder beim Fixen eine gemeinsame Nadel benutzt. Die Aufklärungsbemühungen, die an diesem Punkt ansetzen und auf eine Verhaltensänderung abzielen (safer sex). haben auch durchaus schon Erfolge erzielt, wie sich an den Statistiken über die Geschlechtskrankheiten ablesen läßt. Fatalerweise wirkt sich das aber auf die AIDS-Stati- stiken nur mit erheblicher Verzögerung aus, weil die Inkubationszeit bei AIDS bis zu zehn Jahren und mehr betragen kann. Bei uns erkranken zur Zeit die Personen an AIDS, die sich schon vor Jahren infiziert haben, als es noch keinerlei AIDS-Aufklärung gab. Deshalb werden die AIDS-Zahlen auch in den kommenden Jahren zunächst weiter ansteigen, gleichgültig, was jetzt zur Verhütung von AIDS unternommen wird. Daraus folgern viele völlig zu Unrecht, daß die „Broschürenpolitik” gescheitert sei und daß man „AIDS nicht mit ein paar bunten Broschüren bekämpfen" könne. Einzelne Politiker fordern mit dieser unzutreffenden Begründung die Einführung der Meldepflicht für AIDS sowie die Überwachung und Registrierung der "Risikogruppen", also der Homosexuellen, der Drogenabhängigen und der Prostituierten. Dabei weiß heute jeder Einsichtige, daß AIDS keine Krankheit der "Risikogruppen”, sondern des "Risikoverhaltens" ist. Diese öffentliche Diskussion um die Meldepflicht und um Zwangsmaßnahmen löst bei den Betroffenen verständlicherweise zusätzliche Ängste aus. Denn niemand kann abschätzen, wie hysterisch die Öffentlichkeit in Zukunft auf die zwangsläufig noch lange Zeit ansteigenden AIDSZahlen reagieren wird und zu welchen Reaktionen sich dadurch die Politiker drängen lassen. Hält man sich das aber alles vor Augen, ist es durchaus nachfühlbar, daß Patienten davor zurückschrecken, den „AIDS-Test” bei ihrem Hausarzt oder bei einer für sie unübersichtlichen großen Klinik machen zu lassen, und stattdessen lieber zum Gesundheitsamt oder zu einem Laborarzt gehen, wo sie den Test anonvm machen lassen können oder doch zumindest die Gewißheit haben, daß ihre Personalien absolut vertraulich behandelt werden. Die Ärzte dürfen aber ihre Patienten nicht entmündigen und ihnen diese Wahlmöglichkeit nehmen. Wenn die Rechtsprechung immer wieder betont, daß auch der ärztlich indizierte und kunstgerecht durchgeführte Eingriff nur erlaubt ist, wenn der Patient zuvor umfassend aufgeklärt worden ist und daraufhin in den Eingriff eingewilligt hat, dann steht dahinter der Gedanke des Schutzes des durch Art. 2 Abs. 1 GG gewährleisteten Selbstbestimmungsrechts des Patienten '. Der "AIDS-Test” berührt aber die Intimsphäre des

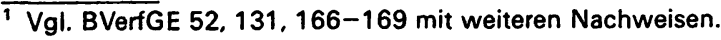


Patienten in ganz besonderer Weise. Deshalb hat bei ihm der Schutz des Selbstbestimmungsrechts des Patienten auch besonderes Gewicht.

Hinzu kommt, daß ein „AIDS-Test” regelmäßig nur indiziert ist, wenn es um die Abklärung entsprechender Symptome geht. Er ist außerdem als Vorsorgeuntersuchung bei solchen Schwangeren angezeigt, bei denen die Möglichkeit besteht, daß sie oder ihre Partner in den vergangenen Jahren nicht absolut monogam gelebt haben. In allen anderen Fällen bringt dagegen die Klärung der Frage, ob eine AIDS-Infektion stattgefunden hat, den Betroffenen und ihren Partnern meist keinen Gewinn. Denn heute müssen alle, die nicht in absolut monogamen. Beziehungen leben, sich bei sexuellen Kontakten grundsätzlich immer auf „safer sex” beschränken, gleichgültig, ob sie oder ihre Partner "positiv" oder "negativ" sind. Ein negatives Testergebnis ist keine Unbedenklichkeitsbescheinigung. Das ist es schon deshalb nicht, weil es durch jeden neuen sexuellen Kontakt ohne Vorsichtsmaßnahmen entwertet wird. Außerdem sind die Tests nicht „sicher", weil sie auf frische Infektionen nicht ansprechen und aus diesem Grund über den gegenwärtigen Gesundheitszustand der getesteten Personen nichts aussagen. Bis die Testreaktion nach einer Infektion positiv wird, können bis zu sechs Monate vergehen. Es ist also unsinnig, sich auf ein negatives Testergebnis zu verlassen, selbst wenn es nur eine Woche alt ist, wenn man nicht sicher weiß, was der andere in dieser Woche und in den letzten sechs Monaten vor dem Test getrieben hat. Und wann weiß man das schon wirklich sicher? Aus diesem Grund ist es auch höchst bedenklich, daß die Gesundheitsbehörden die Öffentlichkeit mit Hinweisen auf die verstärkte Überwachung von Prostituierten und Strichern zu beruhigen versuchen und dabei geflissentlich verschweigen, daß sie trotz aller Kontrollen und Tests für nichts garantieren können. Dadurch erwecken die Gesundheitsbehörden in den Kunden der Prostituierten und Strichern ein falsches Sicherheitsgefühl. Die Kunden vertrauen auf die Überwachung der Prostituierten und Stricher durch die Gesundheitsbehörden und haben deshalb nicht die Vorstellung, daß sie trotzdem selbst für ihre Gesundheit vorsorgen müssen. Es kommt ja nicht von ungefähr, daß Prostituierte und Stricher ihre Kunden neuerdings mit dem Hinweis auf "Gesundheitszeugnisse“ umwerben. Das ist die fatale Folge einer verfehlten Gesundheitspolitik, die ihr Heil in verstärkten Kontrollen und Tests sucht, statt alle Register der modernen Massenwerbung zu ziehen, um jeden Mann und jede Frau, jung und alt, immer wieder darauf hinzuweisen, daß jedes sexuelle Abenteuer lebensgefährlich ist, wenn man sich dabei nicht auf "safer sex" beschränkt.

Bringen also die nicht der Diagnose dienenden „AIDSTests" den Patienten meist keinen Vorteil, so können sie aber andererseits erhebliche schädliche Nebenwirkungen haben. Denn die Konfrontation mit einem positiven Testergebnis löst bei den Betroffenen regelmäßig schwere depressive Verstimmungen aus, die sich bis zur Suizidgefahr steigern können. Es besteht aber Einigkeit darüber, daß solche Beeinträchtigungen des Lebenswillens die Immunabwehr des Körpers schwächen können. Es ist deshalb vorstellbar, daß gerade die durch die Konfrontation mit einem positiven Testergebnis ausgelösten Depressionen der Faktor sind, der das Immunsystem eines infizierten Patienten zusätzlich so schwächt, daß die Krankheit zum Ausbruch kommt. Aus diesem Grund muß der Arzt bei "AIDS-Tests", die nicht der Diagnose dienen, mit seinen Patienten eingehend über die Frage sprechen, ob sie sich einem positiven Testergebnis gewachsen füh- len und ihnen gleichzeitig klarmachen, daß das erhoffte negative Testergebnis sie nicht von der Notwendigkeit entbindet, sich bei sexuellen Kontakten auf "safer sex" zu beschränken.

Das alles zeigt, daß der "AIDS-Test” keine Routineuntersuchung wie die Blutsenkung ist. Deshalb muß der Arzt seine Patienten ausdrücklich um Einwilligung fragen und sie vorher über alle Aspekte des „AIDS-Tests” umfassend aufklären, damit diese sachgemäß abwägen können, ob überhaupt und bei welchem Arzt sie den Test vornehmen lassen wollen. Andernfalls deckt die allgemeine Einwilligung der Patienten in eine Untersuchung und in die Blutentnahme den zusätzlichen „AIDS-Test” nicht mit ab. Die auch zu diesem Zweck vorgenommene Blutentnahme ist in solchen Fällen mangels ausreichender Einwilligung insgesamt rechtswidrig und als Körperverletzung strafbar.

\section{Manfred Bruns}

Bundesanwalt beim Bundesgerichtshof

Geibelstraße 27

7500 Karlsruhe 21

\section{Mitteilungen}

\section{Laborgemeinschaften}

Die Kassenärztliche Vereinigung Pfalz führt in ihrem Rundschreiben 4/86 vom 17. Dezember 1986 u.a. folgendes aus:

Im Rahmen der Umstrukturierung des EBM auf dem Laborsektor in Präsenzlabor, Allgemeinlabor und Speziallabor wurden die häufigsten 34 Parameter der klinischen Chemie mit 40 Punkten angesetzt. Dieser Festsetzung lagen durchschnittlich Kosten von DM 2,50 für die Laborgemeinschaft, DM 0,50 für Probengewinnung und Dokumentation in der Praxis sowie ein ärztliches Honorar von DM 1,00 zugrunde. Die Krankenkassen haben dem nur unter der Bedingung zugestimmt, daß eine flächendeckende und ortsnahe Laborgemeinschaftsstruktur erhalten bleibt.

Selbstverständlich wissen auch die Krankenkassen um die niedrigen Preise der gewerbsmäßigen Großanbieter. Die Kassen haben eindeutig zu erkennen gegeben, daß sie im Falle einer weiteren Konzentration von Ärzten in Großlabors nicht mehr bereit wären, die obigen Preise zu akzeptieren. Nicht nur der neue EBM wäre damit gefährdet, sondern auch das Labor als ureigene kassenärztliche Betätigung würde schon relativ bald aus unserer Verantwortung und auch aus unserem Honorar verschwinden.

Ich muß daher mit der gebotenen Deutlichkeit sagen, daß die KV alle ihr zur Verfügung stehenden Mittel einsetzen wird, um derartigen Fehlentwicklungen gegenzusteuern. Das Prinzip der persönlichen Leistungserbringung wird neben der Überwachungspflicht, der Eingreifmöglichkeit sowie der Beteiligung am finanziellen Erfolg oder Mißerfolg auch bei den Laborgemeinschaften nachhaltig überwacht werden müssen. Kassenärzte, die den obigen Kriterien im Bereich des Labors nicht genügen, müssen damit rechnen, kein Honorar für ihre bezogenen Laborleistungen zu erhalten. 


\section{Aus den Landesgruppen}

\section{Sitzung der Landesgruppe Berlin}

Die Landesgruppe Berlin des Berufsverbandes Deutscher Laborärzte traf sich am 22. Oktober 1986 im Krankenhaus am Urban. Auf der Sitzung wurde u.a. über das Erfordernis der Genehmigung bzw. der Anzeigepflicht bei der Aufnahme mikrobiologischer Untersuchungen gesprochen. Die KV sollte veranlaßt werden, wie bereits in anderen KV-Bereichen, die Ringversuche auf dem Gebiet der Immunhämatologie und Mikrobiologie zur Pflicht zu machen. Weitere Tagesordnungspunkte befaßten sich mit der Liquidationsabführungsverordnung im Land Berlin und der sich dabei ergebenen Sachkostenabrechnung, dem Eichgesetz und der Eichverordnung sowie der Ärztekammerwahl.

Von den Anwesenden wurde einstimmig Dr. Herold erneut als Landesobmann gewählt und Dr. Krause als sein Stellvertreter bestätigt.

\section{Tagung der Landesgruppe Baden-Württemberg}

Am 13. Dezember 1986 tagte die Landesgruppe BadenWürttemberg des Berufsverbandes Deutscher Laborärzte in Stuttgart. Der Landesobmann, Herr Seuffer, berichtete über die erste Sitzung des neuen Vorstandes des Berufsverbandes und stellte den neuen GOÄ-Entwurf vor.

Zur besseren Auswertung virologischer Untersuchungsdaten wurde als erster Schritt vorgeschlagen, die Anzahl HIV-positiver und bestätigter Seren monatlich zu sammeln und an das BGA weiterzuleiten. Für das Jahr 1986 wurde um eine Gesamtmeldung an Herrn Seuffer gebeten.

Im Rahmen einer Diskussion über seltene Untersuchungen wurde festgestellt, daß auf Grund des Kassenarztrechtes nicht einfach Überweisungen an Krankenhausärzte ausgestellt werden können. Deshalb wurde der Beschluß gefaßt, den KVen mitzuteilen, daß die Landesgruppe Baden-Württemberg des Berufsverbandes Deutscher Laborärzte wünscht, Laborärzte in der Klinik für von Laborärzten in der Praxis überwiesene Fälle an der kassenärztlichen Versorgung zu beteiligen.

Im Verlauf der Diskussion über Ringversuche wurde angeregt, die Industrie darauf hinzuweisen, daß es unzulässig ist, die Ergebnisse von Ringversuchen den Ärzten vorzeitig bekanntzugeben.

Bei der Neuwahl des Landesobmannes wurde Dr. Seuffer, Reutlingen, in seinem Amt bestätigt. Als Stellvertreter wurde Dr. Sieder, Stuttgart, als Beisitzer Prof. Dr. KruseJarres, Stuttgart, gewählt.

\section{Personalien}

Dr. rer. nat. R. Burger, Heidelberg, Professor für Immunologie, hat einen Ruf auf die Stelle des Leiters (Direktor und Professor) der Abteilung Immunologie am RobertKoch-Institut des Bundesgesundheitsamtes Berlin erhalten.

Priv. Doz. Dr. Stefan Kaufmann, Max-Planck-Institut für Immunologie in Freiburg, hat einen Ruf auf die C3Professur der Abteilung Medizinische Mikrobiologie und Immunologie der Universität UIm erhalten.

\section{HPLC-Wasser \\ Störungsfreie Trennungen, lange Lebensdauer der Säulen, frei von organischen Substanzen, Schwebeteilchen kontrolliert.}

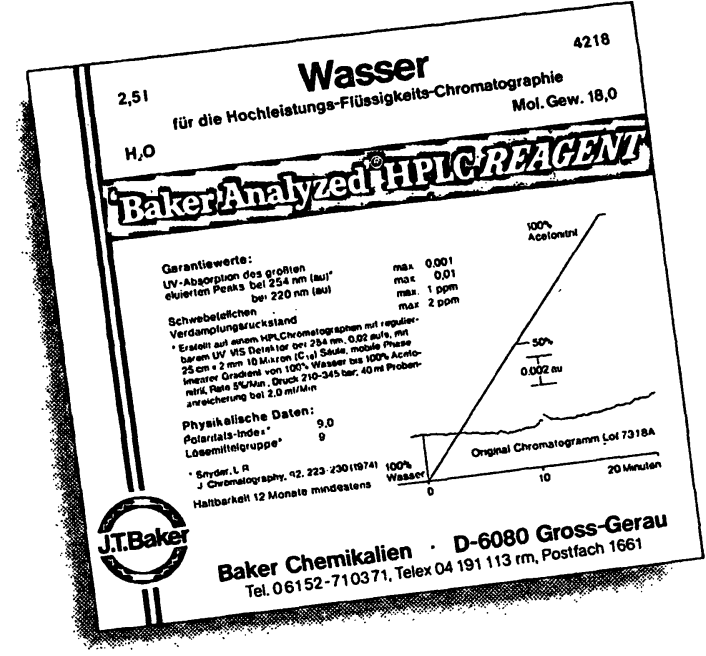

HPLC-Wasservon JT. Baker ist garantiert frei von organischen Substanzen, der gröBte eluierte Peak bei $254 \mathrm{~nm}$ max. 0,001, Schwebestoffe sind auf max. 1 ppm, der Verdampfungsrückstand auf max. $2 \mathrm{ppm}$ begrenzt. Flaschen und Verschlüsse sind besonders gereinigt. $H$ PLC-Wasser ist unter Stickstoff abgefult. Sie knnnen deshalb Pro Baker

Mehr Information über „Baker Analyzed" HPLC-Reagenzien erhalten Sie kostenlos von Baker Chemikalien.

\section{Aus Österreich}

\section{Neuer Vorstand der ÖGKC}

Die Österreichische Gesellschaft für Klinische Chemie wählte auf ihrer Vollversammlung am 19. 9. 1986 in Salzburg einen neuen Vorstand. Prof. Dr. med. Bernd Puschendorf, Leiter der Abteilung für Klinische Biochemie am Institut für Medizinische Chemie und Biochemie der Universität Innsbruck, wurde einstimmig zum Präsidenten gewählt. Weitere Vorstandsmitglieder sind:
Vizepräsident:
Sekretär:
Schatzmeister:
Schriftführer:
Beirat:
Prof. Dr. M. M. Müller (Wien) OR Dr. Erika Dworzak (Innsbruck)
Prim.-Doz. P. Bayer (Wien)
DDr. Alexander Lapin (Wien).
Prof. Dr. F. Gabl (Wien)
Prim. Dr. W. Hohenwallner (Linz)
Dr. Peter Chiba (Wien)
(zuständig für Ausbildungsärzte).
Erweiterter Beirat: Leiter der Nebenstellen
Nebenstelle Wien: Prof. Dr. Erich Kaiser
Nebenstelle Innsbruck: Prof. Dr. Hans Grunicke
Nebenstelle Salzburg: Prim. Dr. Hans Jörg Gibitz
Nebenstelle Linz:
Prim. Dr. Rudolf Sommer
Nebenstelle Graz: Doz. Dr. Walter Petek. 


\section{Aus dem DIN Deutsches Institut für Normung e.V.}

\section{Sitzung des Präsidiums des DIN}

Das Präsidium des DIN trat am 22. Oktober 1986 in Berlin zu seiner 39. Sitzung zusammen. Der Präsident des DIN, Dipl.-Ing. S. Hahn-Wörnle gab in seinem Bericht einen Rückblick über das vergangene Jahr. Neben organisatorischen Veränderungen im DIN, wie der Gründung einer Kommission Gesundheitswesen (KGew) behandelte er sowohl Aktivitäten auf dem Gebiet der internationalen und der europäischen Normung als auch der Zusammenarbeit mit den Entwicklungsländern. Diskutiert wurde die angespannte finanzielle Situation des DIN, die bedingt ist durch einen Absatzrückgang der Normen als Einzelblätter von 1.36 Mio. Stück im Jahre 1976 auf 692000 Stück im Jahre 1985. Als eine Ursache der Erlöseinbuße wird die verbesserte Kopiertechnik angesehen, die die Wirtschaft veranlaßt, statt beim DIN gekaufter Normen kopierte Normen zu benutzen. Der Finanzausschuß hat eine Reihe von Maßnahmen ergriffen bzw. erwogen, die das im Jahre 1985 1,4 Mio. DM aufweisende Defizit abbauen sollen.

Jeder Normenausschuß hat einen eigenen Haushalt, bei dem die Eigenfinanzierungsquote von $0 \%$ bei einem ausschließlich querschnittsbezogenen Ausschuß, wie dem Normenausschuß Einheiten und Formelgrößen (AES), bis zu $100 \%$ bei einem ausschließlich fachbezogenen Ausschuß, wie dem Normenausschuß Feuerwehrwesen (FNFW), bei dem interessierte Kreise (Hersteller, Öffentliche Hand etc.) alle Kosten tragen, schwankt. Der Normenauschuß Medizin (NaMed) nimmt, wie die Mehrzahl der Ausschüsse, eine Zwischenposition ein. Er arbeitet mit einer Eigenfinanzierungsquote von $50 \%$. Das DIN zahlt, einschließlich der ihm für diese Zwecke vom Bundesministerium für Wirtschaft zur Verfügung gestellten Mittel, die Hälfte des Haushalts, während die andere Hälfte durch die Eigenfinanzierung der interessierten Kreise aufgebracht wird.

\section{Kurzzitate}

Durch Thrombozytenagglutination im EDTA-Blut kann es zu einer Pseudothrombopenie bei Verwendung automatischer Zellanalysengeräte kommen. Nachbestimmungen in kapillärem Blut (ohne EDTA) ergeben normale Thrombozytenwerte [Schweiz. med. Wschr. 116, 1566-69 (1986)].

Bei Patienten höheren Alters und weiblichen Geschlechts mit Adipositas war die Immunantwort bei der Hepatitis-B-Impfung auf eine Injektion ins Gesäß deutlich schlechter als bei Injektionen in den $\mathrm{M}$. deltoideus (Kassenarzt aktuell, KV-NordWürttemberg Nr. 20, 25).

Die Bestimmung der Gesamt-T4-Zellzahl mittels der Vollblutmethode ist ein genauer Maßstab, um eine HIV-bedingte T4Zellelimination und dadurch sich entwickelnde Immundefizienz zu erfassen, während der Hauttest gegen Umweltantigene (Multitest) erst bei bereits manifester Immundefizienz wertvoll ist, wie auch die Gesamtlymphozytenzahl [Schweiz. med. Wschr. 116, 1506-1513 (1986)].

Zweimal täglich $500 \mathrm{mg}$ Ciprofloxacin oral über 14 Tage sind das Mittel der Wahl bei erwachsenen Salmonellendauerausscheidern. Rückfälle wurden bei 16 Patienten - bis zu 7 Jahren als Ausscheider bekannt - in 329 Tagen Nachbeobachtungszeit nicht verzeichnet (medwelt 1986, Nr.37, S.52).

Bei 15957 zwischen Juni 1981 und Oktober 1985 untersuchten Schwangeren fand sich $69 \mathrm{mal}(0,4 \%)$ ein positiver TPHA-Test. Bei 180 Schwangeren $(1,1 \%)$ war HBs-Antigen positiv. Von den 13752 deutschen Schwangeren waren $(0,6 \%)$, von den 763 südeuropäischen (3,8\%), von den 1159 aus Vorderasien $(5,1 \%)$ und von den 170 Schwangeren aus Ostasien und sonstigen außereuropäischen Ländern (6.5\%) positiv. Durch Erweiterung der gesetzlich vorgeschriebenen serologischen Mutterschaftsvorsorge-Maßnahmen um die Untersuchung auf HBs-Antigen können die Hepatitis-B-Trägerinnen erfaßt und durch eine passiv-aktive Immunisation der Neugeborenen die maternofetalen Infektionen verhindert werden [Dtsch. med. Wschr. 111, 1757$1760(1986)]$

Ein Vergleich der Magnesiumbestimmung im Serum zwischen der Xylidylblau - Methode und der Atomabsorptions-Spektralphotometrie (AAS) ergab eine deutliche Überlegenheit der AAS bezüglich Linearität, Spezifität, Präzision, Richtigkeit und Interferenzen durch erhöhtes Serum-Bilirubin und durch Lipämie, so daß die Xylidylblau-Methode nicht empfohlen werden kann [Mag.-Bull. 8, 320-332 (1986)]

\section{Eingegangene Bücher}

Schilddrüse 1985. 7. Konferenż über die menschliche Schilddrüse, Homburg/Saar. Henning Symposium Publikation. Hrsg. von P. Pfannenstiel, D. Emrich, B. Weinheimer. 575 Seiten, 181 Abb., 124 Tab., 2 Farbtafeln. Georg Thieme Verlag, Stuttgart, New York, 1986. ISBN 3-13-692901-2.

AIDS. Erworbenes Immundefekt-Syndrom. Ein Farbatlas. Von C. F. Farthing, S. E. Brown, R. C. D. Staughton, J. J. Cream, M. Mühlemann. 80 Seiten, 214 farbige Abb. u. 2 Tab., gebunden. Schwer Verlag, Stuttgart, 1986. ISBN 3-89272-000-2. DM 48,-.

Lehrbuch der Allgemeinmedizin. Theorie, Fachsprache und Praxis. Neue Allgemeinmedizin, Band 4. Von R. N. Braun. 208 Seiten, 25 Abb., 12 Tab., 188 Prüfungsfragen im MultipleChoice-System, kartoniert. Verlag Kirchheim, Mainz, 1986. ISBN 3-87409-123-6. DM 58,- .

Einführung in die Immunbiologie. Von Dr. G. M. Hänsch. $X$. 280 Seiten, $147 \mathrm{Abb}$., 45 Tab., kartoniert. Gustav Fischer Verlag Stuttgart, 1986. ISBN 3-437-20365-7. DM 26,80.

Doktor und Poet dazu. Dichterärzte aus fünf Jahrhunderten. Von W. Theopold, 1.Aufl. 400 Seiten mit zahlreichen Abb., gebunden. Verlag Kirchheim, Mainz, 1986. ISBN 3-87409-024-8. DM 39,80.

"AIDS aktuell". Von Goebel/Gauweiler. Loseblattsammlung. 1. Ergänzungslieferung. 148 Seiten. Verlag R. S. Schulz, Percha. DM 41,- .

Labormanual. Von W. Klietmann. XIV, 410 Seiten, 26 Abb. Kunststoffeinband. Schattauer Verlag, Stuttgart, New York, 1986. ISBN 3-7945-1117-4. DM 46,- .

Die Gegenstromimmunelektrophorese. Prinzip und klinische Anwendung in der Pädiatrie. Von W. Storm. VIII, 87 Seiten, 12 Abb., 36 Tab. kartoniert. Gustav Fischer Verlag, Stuttgart, 1987. ISBN 3-437-11087-X. DM 48,-

Funktion und Funktionsdiagnostik der Leber. Hrsg. von D. Seidel, H. Lang. Unter Mitarbeit von M. Nauck. Deutsche Gesellschaft für Klinische Chemie/Merck-Symposium 1985 (Zusammenarbeit von Klinik und Klinischer Chemie). 190 Seiten, $67 \mathrm{Abb}$. und $21 \mathrm{Tab}$., kartoniert. Springer-Verlag, Berlin, Heidelberg, New York, 1987. ISBN 3-540-16963-6.

Asthma Alveolitis Aspergillose. Charakterisierung ursächlicher Antigene. Von X. Baur. 122 Seiten, 53 Abb., 18 Tab., gebunden. Springer-Verlag, Berlin, Heidelberg, New York, 1986. ISBN 3-540-16523-1

Techniken der Injektion. Von H. Kaiser und W. Fischer, 5. Aufl., 84 Seiten mit zahlreichen Abbildungen, kartoniert. Selecta-Verlag Dr. Ildar Idris, Planegg, 1985.

Die Adenylchemie GmbH Berlin hat einen Teil der Auflage übernommén und stellt inn interessierten Ärzten kostenlos auf Anfrage zư Verfügung. 


\section{Fortschritt und Fortbildung in der Medizin}

IX. Interdisziplinäres Forum der Bundesärztekammer 9. bis 12. Januar 1985

Hrsg. von der Bundesärztekammer, Band IX 1985/86, 408 Seiten, zahlreiche $A b b$. und Tab., gebunden. Deutscher Ärte-Verlag, Köln, 1985. ISBN 3-7691-0101-4. DM 20,-

Mit dem IX. Band „Fortschritt und Fortbildung in der Medizin” liegen die Referate und Diskussionen des IX. Interdisziplinären Forums der Bundesärztekammer vom 9. bis 12. Januar 1985 vor. Diese schon traditionell in der ersten Januarhälfte jeden Jahres stattfindende Veranstaltung dient der Mitteilung neuer gesicherter Forschungsergebnisse. In der Diskussion soll auch aufgezeigt werden, welche Methoden als obsolet aufgegeben werden müssen. Die Schwerpunkte der sich durchweg durch hohes Niveau auszeichnenden Vorträge befaßten sich mit den Folgeerkrankungen des Alkoholismus, den sexuell übertragenen Infektionserkrankungen, die wir bereits in Lab.med. 9: BDL 41-43 (1985) referiert haben, der ärztlichen Versorgung am Unfallort, neuen Erkenntnissen zur Diagnostik und Therapie bei allergischen Erkrankungen, der Anorexia nervosa, dem Schicksal von Gelenkimplantaten sowie der extrakorporalen Fertilisation und anderen nicht hormonalen Methoden zur Behandlung der Unfruchtbarkeit. Neben den Literaturangaben sind auch die lesenswerten lebendigen Diskussionsbemerkungen abgedruckt. Der niedrige Preis des hervorragend ausgestatteten Bandes lohnt die Anschaffung für jeden, der sich für eines dieser Gebiete interessiert.

W. H.

\section{Electrophoresis '86}

Proceedings of the Fifth Meeting of the International Electrophoresis Society, London 1986

Hrsg. von M. J. Dunn, 765 Seiten, 231 Abb., 37 Tab. XVIII, kartoniert. $V C H$ Verlagsgesellschaft, Weinheim, 1986. ISBN 3527-26566-X. 180,-DM.

Der Sammelband mit 145 Einzelbeiträgen (Vorträgen und Posters, alle entsprechend dem Autorenmanuskript mit Tabellen und Abbildungen versehen) sowie einem umfangreichen Register fügt sich homogen an Electrophoresis ' 84 an (vgl. Lab. med. 9: BDL 74, 1985). Eine Vielzahl von Informationen und neuen Erfahrungen zu den folgenden Teilbereichen werden präsentiert: Zell-Elektrophorese, Free-Flow-Elektrophorese, Elektrophorese von Nukleinsäuren, Proteinelektrophorese in Agarose- oder Polyacrylamidgel, Isoelektrische Fokussierung, 2-D PAGE und präparative Elektrophorese. Bereits die Verteilung der Beiträge auf die einzelnen Gebiete läßt die zunehmende Bedeutung hochtechnisierter Trenn- und Detektionsverfahren in Medizin, Biologie, Mikrobiologie, Virologie, Genetik einschließlich forensischer Fragestellungen sowie den Agrarwissenschaften erkennen. Ein deutlicher Trend zur EDV-gesteuerten Automatisation weist darauf hin, daß die hier diskutierten Verfahren bald Einzug in die Routine-Diagnostik finden werden, weshalb auch dem Laborarzt eine frühzeitige Beschäftiguñng mit der Thematik anempfohlen sei. In diesem Sinn kann der Erwerb und vor allem die Lektüre des ansprechend aufgemachten Bandes als (Teil-) Ersatz für den Besuch der Tagung in London trotz seines hohen Preises als lohnende Investition angesehen und empfohlen werden.

B. Ziegler

\section{AIDS aktuell}

\section{Medizin - Organisation - Recht}

Hrsg. von F.-D. Goebel, P. Gauweiler. 960 Seiten, Loseblattausgabe. Verlag R. S. Schulz, Percha, 1986. ISBN 3-7962-0344-2. DM 58, -.

Das erworbene Immundefekt-Syndrom (AIDS) ist die z.Zt. nicht nur Ärzte, Gesundheitsämter und Gesetzgeber sondern auch die Allgemeinheit beschäftigende Erkrankung. Die. Identifizierung des Erregers hat die Möglichkeit eröffnet, therapeutische Maßnahmen zu entwickeln. Da aber eine effektive Behandlung oder

\section{Scheidetrichter ade, ab jetzt nur noch mit BAKER-10 SPE}

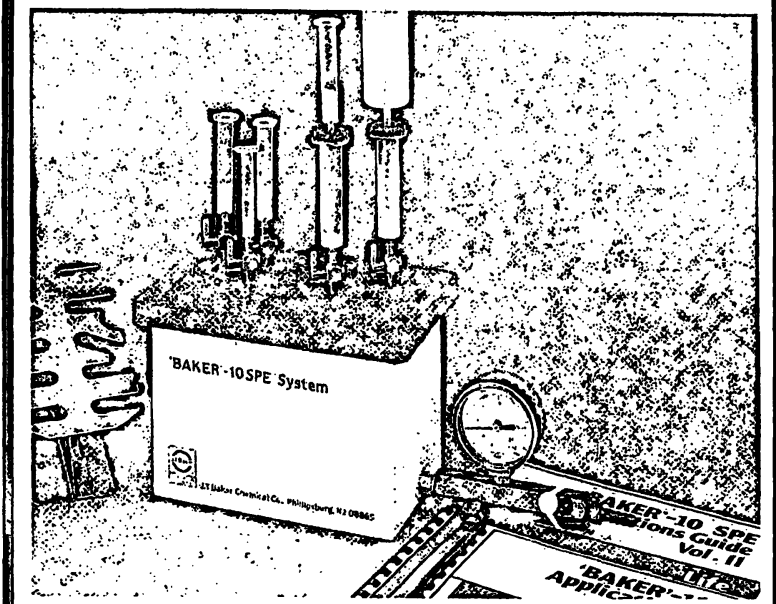

Probenvorbereiten ist jetzt einfach,

sparsam und schnell mit dem BAKER-10 SPE (Solid Phase Extractions) System und den Trennsäulen. Unterschiedliche an Silicagel gebundene funktionelle Gruppen adsorbieren selektiv aus der Matrix. Dabei durchlaufen Probe und Eluat die fertiggepackte Trennsäule mit Hilfe von Vakuum. Mit weniger als $10 \%$ bisheriger Lösemittelmengen werden bis zu 10 Proben gleichzeitig in etwa 10 Minuten vorbereitet. Von Baker gibt es dazu Band I und II des Applications Guides und kostenlos über 175 Anwendungshinweise und Literaturstellen. Unterlagen bitte anfordern.

Baker Chemikalien, Postfach 1661, 6080 Groß-Gerau, Telefon (06152) 710378

medikamentöse Prävention durch Impfung bisher nicht möglich ist, ist eine weitere Ausbreitung des Virus unvermeidlich. Die einzige Maßnahme, die z.Zt. ergriffen werden kann, ist eine intensive Aufklärung der Bevölkerung, um eine Änderung der Lebensgewohnheiten zu erreichen. Naturgemäß ruft eine Erkrankung, die einen solch breiten Raum im Bewußtsein der Allgemeinheit einnimmt, eine Flut von Veröffentlichungen hervor.

Ein umfangreiches Werk hat jetzt der Verlag R. S. Schulz unter dem Titel "AIDS aktuell" herausgegeben, bei dem seit Januar 1986 die Monatszeitschrift „AIDS-Forschung” erscheint. Es handelt sich um eine Loseblattsammlung von über 900 Seiten, die in einen medizinischen Teil der von Frank-Detlef Göbel von der Medizinischen Poliklinik der Universität München und einen Teil "Organisation/Verwaltung/Recht", der von Dr. Peter Gauweiler, berufsmäßiger Stadtrat in München, bearbeitet ist.

Der medizinische Teil ist gegliedert in historische Entwicklung, Epidemiologie, Ätiologie, Pathogenese, Klinik, Diagnose, Therapie, Prognose, Prophylaxe und psychosoziale Aspekte von AIDS Es handelt sich bei diesem Teil um Merkblätter des Bundesgesundheitsamtes und Originalarbeiten aus medizinischen Zeitschriften, wie der Schweiz. Med. Wschr., der Münch. Med. Wschr., dem Deutschen Ärzteblatt, der Klin. Wschr., der Deutschen Med. Wschr. und nicht zuletzt der AIDS-Forschung. Zum Teil werden auch Arbeiten aus Bundesgesundheitsblatt, Immunität und Infektion, Internist, Prax. Klin. Pneumol. und Z. Hautkr. referiert.

Der zweite Teil gliedert sich in: Maßnahmen des Bundes zur AIDS-Bekämpfung, Krankheitsbekämpfung/Seuchenwesen, Strafrecht/Strafprozeßrecht/Strafvollzugsrecht, LandesrechtVeröffentlichungen und Maßnahmen/ausländisches Recht. Einen großen Teil nimmt der stenographische Bericht der Öffentlichen Anhörung des Bundestagsausschusses ,Zur Bekämpfung des erworbenen Immunmangelsyndroms und der Maßnahmen gegen AIDS" ein. Wir haben über diese Anhörung bereits in Lab.med. 10, BDL 67 (1986) berichtet. Interessant ist es jetzt. die Diskussionsbemerkungen im vollen Wortlaut nachzulesen. 
Abgedruckt ist außerdem das Bundesseuchengesetz und das $\mathrm{Ge}$ setz zur Bekämpfung der Geschlechtskrankheiten. Entsprechende Auszüge aus dem Strafgesetzbuch, der Strafprozeßord. nung und dem Strafvollzugsgesetz schließen sich an. Unter dem Kapitel Landesrecht werden Verordnungen und Ausführungsvorschriften vorwiegend zum Bundesseuchengesetz wiedergegeben. Unter dem ausländischen Recht findet sich das österreichische Bundesgesetz über Maßnahmen gegen die Verbreitung des erworbenen Immundefekt-Syndroms (AIDS-Gesetz) vom 16. Mai 1986. Nach diesem Gesetz sind manifeste Erkrankungen und Todesfälle meldepflichtig. Zu melden sind die Initialen, das Geburtsdatum und das Geschlecht des Kranken bzw. Verstorbenen.

Für die vorliegende Loseblatt-Literatursammlung, die sich auf das deutschsprachige Schrifttum beschränkt, sind regelmäßige Ergänzungslieferungen konzipiert. Jeder, der sich unter medizinischen oder juristischen Aspekten mit dieser Krankheit zu beschäftigen hat, wird, sofern er das Schrifttum nicht selbst sorgfältig verfolgen will, auf diese Veröffentlichung zurückgreifen. Ein noch fehlendes - Sachverzeichnis würde sie noch benutzerfreundlicher gestalten.

W. H.

\section{History of Clinical Chemistry}

Hrsg. J. Büttner, 91 Seiten, gebunden. Walter de Gruyter \& Co., Berlin, 1983. ISBN 3-11-008912-2. DM 98,-.

Der vorliegende Band enthält acht im Journal Clin. Chem. Clin. Biochem. in den Jahren 1978 bis 1982 veröffentlichte Arbeiten, die auf Vorträge zurückgehen, die bei verschiedenen Anlässen gehalten wurden; drei davon stammen vom Herausgeber. Sie beschäftigen sich mit dem historischen Hintergrund und der $\mathrm{Be}$ ziehung zwischen Chemie, Biochemie und Medizin im 19. Jahrhundert, bei der Entwicklumg der-klinischen Enzymologie darüber hinaus bis zur ersten Hälfte des 20. Jahrhunderts. Zwei Aufsätze sind Einzelpersönlichkeiten, Johann Josef von Scherer und Eugen Franz Freiherr von Gorup-Besanez gewidmet. Es handelt sich um eine Zeit außergewöhnlicher Fortschritte auf dem Gebiet der Naturwissenschaften, die für die heutige Bedeutung der Chemie in der Medizin richtungweisend war. Der unangemessen hohe Preis dürfte einer weiten Verbreitung des Werkes hinderlich sein.

W. H.

\section{Zoonosen}

Von Tier zu Mensch übertragbare Infektionskrankheiten. Leitfaden für die Praxis

Hrsg. von H. Krauss u. A. Weber. 374 Seiten, 90 Abb., 50 Tab., gebunden. Deutscher Ärte-Verlag, Köln, 1986. ISBN 3-76910099-9. DM 138,-

Zoonosen oder Zooanthroponosen sind nach der 18. Auflage des Großen Brockhaus Tierseuchen, die auf den Menschen übertragbar sind. 1958 hat ein Expertenkomitee der WHO Zoonosen definiert als „Krankheiten und Infektionen, die auf natürlichem Wege zwischen Wirbeltieren und Menschen übertragen werden“. In dem vorliegenden "Zoonosen" betitelten Buch berichten sieben human- und veterinärmedizinische Bakteriologen, Virologen und Parasitologen, jedoch auch über Erkrankungen, die, wie z.B. die enteralen Yersiniosen sowohl beim Tier als auch beim Menschen vorkommen, bei denen aber die Infektkette TierMensch bisher nicht sicher belegt werden konnte. Sie bezeichnen derartige Erkrankungen als "Sapronosen" oder "Saprozoonosen", ein Begriff, den der Große Brockhaus nicht kennt. Die Bezeichnung ist sicher vom griechischen sapros $=$ faul, verfault, abgeleitet. Die WHO-Definition für Zoonosen trifft auch für eine Reihe von Parasitosen, neben vielen anderen Z.B. die Malaria, nicht zu, da als Zwischenwirt keine Wirbeltiere fungieren.

Der Band ist eingeteilt in die Kapitel: Durch Bakterien (einschließlich Rickettsien- und Chlamydien), durch Pilze, durch Viren und durch Parasiten hervorgerufene Zoonosen. Die durchgehaltene Gliederung bei jedem Krankheitsbild in Ätiologie, Vorkommen und Verbreitung, Übertragung, Krankheitsbild, Diagnose, Differentialdiagnose, Therapie, Prophylaxe, Hinweise auf das Bundesseuchengesetz und weiterführende Literaturangaben wahrt eine Einheitlichkeit, die das Mitwirken mehrerer Autoren nicht erkennen läßt. Bei vielen Krankheitsbildern sind die Entwicklungszyklen schematisch wiedergegeben. Vereinzelt sind auch die Verbreitungsgebiete auf einer Karte veranschaulicht. Die durchweg farbigen Abbildungen der klinischen Erscheinungsbilder beschränken sich auf einige wenige Krankheiten. Ein Schema, das der Bildauswahl zugrunde lag, läßt sich nicht erkennen. Vereinzelt finden sich mikroskopische Bilder, die sich aber zum Beispiel bei den Wurmeiern auf Eiballen von Dipylidium caninum beschränken.

Bedingt durch den zunehmenden Ferntourismus muß mit dem Einschleppen von unbekannten Zoonosen gerechnet werden, wie auch durch den vielfach illegalen Transport exotischer Tiere, Verdienstvoll ist daher die Beschreibung bei uns bisher weitgehend unbekannter Erkrankungen, besonders der Viruserkrankungen. So werden bei den durch Arboviren verursachten Enzephalitiden außer der bei uns bekannten Frühsommer-Meningoenzephalitis elf weitere meist außereuropäische Enzephalitiden besprochen.

Seinen Wert gewinnt das Buch erst durch den tabellarischen Anhang, in dem neben der Wahl des Untersuchungsmaterials zum Nachweis der verschiedenen Zoonosen und der häufig angewandten serodiagnostischen Methoden die virusbedingten Zoonosen mit regional begrenzter Verbreitung nach Erdteilen mit der klinischen Symptomatik und in einer weiteren Tabelle mit den Leitsymptomen Meningitis/Enzephalitis und hämorrhagisches Fieber ausgeführt sind. So ist es möglich, sich bei der Erkrankung von Fernreisenden über die Erkrankungsmöglichkeiten und den einzuschlagenden Weg, um zu einer Diagnose zu gelangen, zu informieren. Der Untertitel des Buches "Leitfaden für die Praxis" ist damit erfüllt. Eine Zusammenstellung, die eigentlich nahe liegt, vermißt man: Welche Erkrankung kann bei Kontakt mit einem bestimmten Tier auftreten? So Z.B., daß beim Zeckenbiß in unseren Breiten nicht nur eine FSME, sondern auch eine Lyme disease in Frage kommt.

W. H.

\section{Tagungen}

Edinburgh (England): 2. bis 5. April 1987 - Symposium of the Institute of Medical Laboratory Sciences.

Themen: Histopathology / Bacteriology / Virology.

Auskunft: Institute of Medical Laboratory Sciences, Secr. J. K. Fawcett, 12, Queeri Anne St., GB-London WIM OAU.

Northern Ireland (Großbritannien): 3. bis 5. April 1987 - Symposium of the Institute of Medical Laboratory Sciences.

Themen: Mourne ' 87.

Auskunft: Institute of Medical Laboratory Sciences, Secr. J. K. Fawcett, 12, Queen Anne St., GB-London WIM OAU.

York (England): 3. bis 5. April 1987 - Symposium of the Institute of Medical Laboratory Sciences.

Themen: Clinical Chemistry / Haematology / Blood group serology / Immunology.

Auskunft:Mr. K. V. Lewis, Pathology Dept., Royal Infirmary, GB-Bradford, West Yorkshire BD 9 6RJ und Institute of Medical Laboratory Sciences, Secr. J. K. Fawcett, 12, Queen Anne St., GB-London WIM OAU.

Mannheim: 4. April 1987 - Kolloquium über Prostaglandine, Leukotriene und andere Eicosanoide im Rahmen des Lesser-LoeweKolloquium.

Themen:Die Rolle von Eicosanoiden bei der Entzündung / Prostaglandine Thromboxane und Nierenfunktion / Eicosanoide in Pathogenese und The rapie kardiovaskulärer Erkrankungen / Die Bedeutung von Prostaglandinen und Leukotrienen in der Gastroenterologie / Leukotriene und die Leber / Eicosanoide und Fortpflanzung.

Auskunft: Institut für Klin. Chemie, Klinikum Mannheim der Universität Heidelberg, Theodor-Kutzer-Ufer, 6800 Mannheim, Tel.:0621/3832222.

Genf (Schweiz): 13. bis 15. April 1987 - Gemeinsame Tagung tropenmedizinischer und parasitologischer Gesellschaften der Bundesrepublik Deutschlands, Belgiens, der Niederlande, Österreichs und der Schweiz.

Themen! -Tropical diseases of man and animals / Tropical diseases and transhumance / Primary health care in the tropics / Nutrition and nutritional 


\section{Quid novi? \\ Medtro-CEA-Eia}

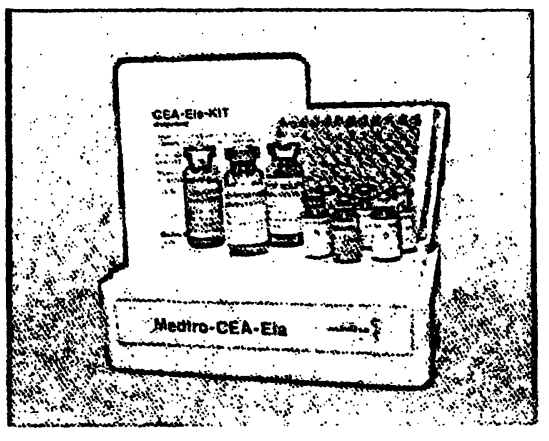

monoklonal

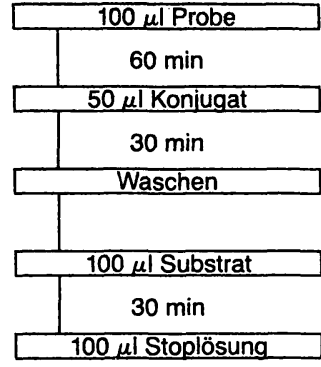

Beschichtete Mikrotiter-Platten, teilbar in 6 Riegel. Deshalb sparsamer Einsatz. Zwei Stunden Gesamtinkubation bei $37^{\circ} \mathrm{C}$.

Nähere Informationen: Medtro GmbH, Höhenstraße 2 6906 Leimen-Gau. Telefon (06226) 8778

disorders / Practical aspects of working in the tropics / Echinococcosis / Cysticercosis / Trichinellosis / Tocoxariasis / Intestinal parasites / AIDS / Opportunistic parasitic infections / Tickborne diseases / Free contribution. Auskunft: Congress Secretariat, SSTMP, Chantemerie 22, CH-2000 Neuchâtel.

Bern (Schweiz): 23. bis 25. April 1987 - 46. Jahreskongreß der Schweizerischen Gesellschaft für Mikrobiologie.

Themen: Ëpidemiologie, Pathogenes und Diagnostik viraler und bakterieller Krankheiten aufgrund molekularbiologischer Verfahren und Erkenntnisse.

Auskunft: Prof. Dr. med. H. Koblet, Univ. Bern, Inst. f. Hygiene und med. Mikrobiologie, Friedbühistr. 51, CH-3010 Bern, Tel.: 0041 - 31 / 643585.

Wiesbaden: 26. bis 30. April 1987 - 93. Tagung der Deutschen Gesellschaft für Innere Medizin.

Themen: Die Bedeutung der Organtransplantation f. d. Innere Medizin / Immunpathologie / Immunmodulation / Neuroendokrinologie oder die Neue Endokrinologie / Diabetes mellitus / Hochdruck- u. Nierenkrankheiten.

Auskunft: Prof. Dr. Dr. E. F. Pfeiffer, Univ., Zentrum Innere Medizin, Steinhövelstr. 9, 7900 Ulm.

Brūssel (Belgien): 27. bis 29. April 1987 - XXXVth Colloquium Protides of the Biological Fluids.

Themen: Conformation and function of biologically active peptides / Preceptors and their defects / DNA probes for the genetic diseases.

Auskunft: Prof. H. Peeters, Colloquium Protides of the Biological Fluids, Inst. f. Med. Biology, Alsembergsesteenweg 196, B-1180 Brüssel, Tel.: $0032 / 2 / 2480511$ ext. 522-523.

Günzburg: 6. bis 9. Mai 1987 - 13. Symposium der Deutschen Gesellschaft für Infektiologie.

Auskunft: Deutsche Gesellschaft für Infektiologie e.V., Geschäftsstelle, Kölner Platz 1, 8000 München 40, Tel.: 089/3068601.

Osnabrück: 7. bis 8. Mai 1987 - Seminar: Einführung in die Krankenhaushygiene.

Themen: Einführung i. d. Problematik / Grundlagen d. Mikrobiologie / Keimquellen i. KH / Maßnahmen z. Verhütung v. Krankenhausinfektionen / Organisation / Grundlagen d. Desinfektion u. Sterilisation / Wirtschaftl. Aspekte.

Auskunft: Inst. f. Krankenhaushygiene u. Infektionskontrolle, Neuwiesenweg 1, 6302 Lich 1.

München : 8. bis 9. Mai 1987 - Gemeinsame Tagung des Berufsverbandes Deutscher Nuklearmediziner und der Bayerischen Gesellschaft für Nuklearmedizin.

Themen: Strahlenschutz und Nuklearmedizin.

Auskunft:Dr. D.W. Nitz, Weinstr. 3, 8000 München 2, Tel.: 089/222118.

Düsseldorf: 11. bis 12. Mai 1987 - 10th World Chromatography and 8th World Spectroscopy Conference.

Auskunft: Dr. V. M. Bhatnagar, Alena Enterprises of Canada, P.O. Box 1779, Cornwall, Ontario K6 H 5V7, Canada.

Eastbourne (England): 11. bis 14. Mai 1987 - Congress of Clinical Chemistry.

Themen: Biochemistry / Prenatal diagnosis / Methodology.

Auskunft: Dr. J. Cook, Biochemistry Dept., Royal Sussex County Hospital, GB-Brighton, Sussex BN2 5BE, Tel.: 0044/273/60611 ext. 141.
Tübingen: 11. bis 15. Mai 1987 - Einführung in den Radioimmunoassay.

Auskunft: Universität Tübingen, Arbeitsstelle Wissenschaftliche Fort- und Weiterbildung. Wilhelmstr. 5, 7400 Tübingen, Tel.: $07071 / 29-5010$ oder 29-6439.

Wien (Osterreich): 15. bis 16. Mai 1987 - Fortschritte in der Diagnose $u$. Therapie hämatologischer $u$. hämostaseologischer Erkrankungen als Ergebnis des Zusammenwirkens theoretischer $u$. klin. Forschung.

Themen: Akute Leukämie / Therapie hämatologischer Erkrankungen / Therapie v. Gerinnungsstörungen.

Auskunft: Prof. Dr. K. Lechner, I. Med. Univ. Klinik, Lazarettgasse 14. A-1090 Wien.

Berlin (Ost): 19. bis 23. Mai 1987 - International Working Conference.

Themen: Progress in biological function analysis by computer technologies.

Auskunft: Prof. Dr. J. L. Willems, div. Med. Informatics, Univ. Hospital, Gasthuisberg, 49 Herestraat, B-3000 Leuven.

Erfurt (DDR): 20. bis 23. Mai 1987 - 5th Intern. Meeting of the Danubian League against Thrombosis and Haemorrhagic Diseases.

Themen: Diagnosis of thrombophilic states / Prophylaxis and therapy of thrombosis / Diagnosis and treatment of haemorrhagic disorders.

Auskunft: Prof. Dr. Fritz Markwardt, Dir. d. Inst. f. Pharmakologie u. Toxikologie, Med. Akad., Nordhäuser Str. 74, DDR-5060 Erfurt, Tel.: 003761 793020

Basel (Schweiz): 22. bis 23. Mai 1987 - 18. Jahresversammlung der Schweizerischen Vereinigung f. Kleintiermedizin.

Themen: Labor i. d. Kleintierpraxis: Aussagekraft, Beurteilungskriterien, Zoonosen.

Auskunft: Dr. R. Equey, Birkenstr. 35, CH-4055 Basel.

Laxenburg (Österreich): 22. bis 23. Mai 1987 - 13. Gemeins. Tagung der Osterr. Ges. f. Urologie u. d. Bayer. Urologenvereinigung.

Themen: Die höhere Labordiagnostik i. d. Urologie / Blutgerinnung i. d. Urologie / Leberdiagnostik / Mykologie.

Auskunft: Univ.-Doz. Dr. P. P. Figdor, Urolog. Abt. Kaiser-Franz-JosephSpital, Kundratstr. 3, A=i 100 Wien, Tel.: 0043/222/641691255.

Taormina-Giardini Naxos (Italy): 22. bis 27. Mai 1987 - 6th Mediterranean Congress of Chemotherapy.

Themen:Antimicrobial Chemotherapy (Chemotherapy and control of bacterial, chlamydial, rickettsial, mycoplasmal, viral, mycotic and parasitic infections) / Anticancer Chemotherapy.

Auskunft: Scientific Secretariat, Institute of Microbiology, Via Androne 81, 1-95124 Catania, Tel.: 094/329880-312798 - 312651.

Halle (DDR): 25. bis 27. Mai 1987 - 5. Symposium f. klinische Endokrinologie.

Themen: Endokrinologie u. interdisziplinäre Kooperation.

Auskunft: Dr. K. Schneyer, Univ., DDR-4020 Halle.

Martinsried: 28. bis 30. Mai 1987 - Jahrestagung der Gesellschaft für Genetik.

Themen: Humangenetik / Immungenetik / Antitumor- und Tumor-Gene / Differenzierung / Evolution. 
Auskunft: Dr. R. Renkawitz. Max-Planck-Inst. f. Biochemie, Am Klopferspitz. 8033 Martinsried, Tel.: 089/85 78-3972.

Washington, D. C. (U.S.A.): 1. bis 5. Juni 1987 - III. International Conference on AIDS.

Auskunf: Intern. Conference on AIDS, 655 15th Street, N.W., Suite 300. Washington, D.C. 2005, USA. Tel.: 202/347-5900.

Tübingen: 22. bis 26. Juni 1987 - Einführung in die Flüssig-Szintillations-Meßtechnik.

Auskunft: Universität Tübingen, Arbeitsstelle Wissenschaftliche Fort- und Woiterbildung, Wilhelmstr. 5, 7400 Tübingen, Tel.: $07071 / 29$-5010 oder 296439.

Tübingen : 22. bis 26. Juni 1987 - Analytische Chemie in der Toxikologie.

Auskunft: Arbeitsstelle Wissenschaftliche Fort- und Weiterbildung, Wilhelmstr. 5. 7400 Tübingen, Tel.: $07071 / 29-5010$ u. 29-6439.

\section{Terminkalender}

\section{Februar 1987}

26. -28.2

Essen: Spezialkurs zum Erwerb der Fachkunde im Strahlenschutz als ermächtigter Arzt (BDL 1986, 7)

\section{März 1987}

März

Mär Nottingham: Symp. of the Inst. of Medical Lab. Sciences

Banff: Int. Symp. on Technological Advances in Lab. Hematology (BDL 1987, 7) (BDL 1987, 7)

1.- 6. 3. Washington: Annual Meeting of the American Society for Microbiology (BDL 1986, 120)

2.- 6. 3. Freiburg: Humane monoklonale Antikörper: Herstellung u. Anwendung (BDL 1987, 7)

4.- 7. 3. Münster: Symp. d. Deutschen Ges. f. Endokrinologie (BDL 1986, 7)

5.- 6. 3. Osnabrück: Seminar: Einführung in die Krankenhaushygiene (BDL 1987, 7)

5.- 7. 3. Essen:Strahlenschutzkurs f. Mediziner u. Nichtmediziner (BDL 1987, 7)

7. 3. Münster: Practicum Allergologicum (BDL 1987, 7)

7. 3. Würzburg: Malaria (BDL 1987, 7)

12.-14. 3. Essen: Spezialkurs zum Erwerb d. Fachkunde im Strahlenschutz als ermächtigter Arzt (BDL 1987, 7)

22. -27. 3. Jerusalem: Int. Symp. on the Immunology of the Gastrointestinal Tract and the Liver (BDL 1987, 7)

25.-27. 3. Edinburgh: Symp. d. British Society for Parasitology (BDL 1987, 7)

26.-28. 3. Wien: Harnstein-Symposium Bonn-Wien (BDL 1987, 7)

27.-28. 3. Essen: Überzeugend sprechen. Ein Intensiv-Seminar f. Mediziner (BDL 1987, 7)

31. 3.- 3. 4. Lübeck: Tagung d. Gesellschaft f. Immunologie (BDL $1987,7)$

April 1987

2.- 5. 4. Edinburgh: Symp. of the Institute of Medical Lab. Sciences (BDL 1987, 14)

3.- 5. 4. Northern Ireland: Symp. of the Institute of Medical Lab. Sciences (BDL 1987, 14)

3.- 5. 4. York: Symp. of the Institute of Medical Lab. Sciences (BDL 1987, 14)

4. 4. Mannheim: Lesser-Loewe-Kolloquium (BDL 1987, 14)

4.- 7. 4. Nizza: ISPO Symp. on Immunobiology in Clinical Oncology and Immune Dysfunctions (BDL 1987, 7)

13.-15. 4. Genf: Gemeins. Tagung tropenmed. u. parasitologischer Gesellsch. der Bundesrepublik Deutschlands, Belgiens, Niederlande, Österreichs u. d. Schweiz (BDL 1987, 14)

13.-18. 4. Tübingen: Grundkurse in Gaschromatographie f. Chemiker u. qualifizierte Mitarbeiter aus den Lab. (BDL 1987. 7)

23.-25. 4. Bern: Jahreskongreß d. Schweizer Ges. f. Mikrobiologie (BDL 1987, 15)

26.-30. 4. Wiesbaden: 93. Tagung der Deutschen Gesellschaft $f$ Innere Medizin (BDL 1987, 15)

27.-29. 4. Brüssel: $X X X V$ th Colloquium Protides of the Biological Fluids (BDL 1987, 15)
Ljubljana (Yugoslavia): 28. Juni bis 3. Juli 1987 - 18th FEBS Meeting organized by the Union of the Biochemical Societies of Yugoslavia.

Auskunft: Secretariat of the 18th FEBS Meeting. J. Stefan Inst., Dept. of Biochemistry, Jamova 39, YU.61000 Ljubljana.

The Hague (The Netherlands): 28. Juni bis 4. Juli 1987 - 13th International / 7th European Congress of Clinical Chemistry. Auskunft: NVKC Office, Boven Vredenburg 65, NL-3511 CW Utrecht.

Cologne: 27 . bis 29 . Juli 1987 - 3rd International Symposium The Influence of antibiotics on the host-parasite relationship.

Themen:The influence of antibiotics on the immune system / The influence of antibiotics on unspecific host-defense mechanismus / The influence of antibiotics on virulence factors / The influence of antibiotics on the interaction of bacteria with the host defence mechanism.

Auskunft: Prof. Dr. G. Pulverer, Inst. of Hygiene, Goldenfelsstr. 19-21. 5000 Cologne 41.

\section{Mai 1987}

6.- 9. 5 .

7. -8.5 .

8.- 9. 5 .

11. -12.5

11. -14.5

11. -15 . 5

15. -16.5

19. -23.5

20. -23.5 .

21. -23 . 5 .

22. 5.

22. -23.5

22. -23.5

22. -27.5 .

25:-27. 5

28. -30.5

Juni 1987

1. -5.6

9. -13.6 .

14. -19.6 .

19.-24. 6 .

21. -26.6

22. -26.6 .

22. -26.6

24. -28 . 6 .

28. 6. - 3. 7. Ljubljana: 18th FEBS Meeting organized by the Union of the Biochemical Societies of Yugoslavia (BDL 1986, 16)

28. 6. - 4. 7. The Hague: 13th International/7th European Congress of Clinical Chemistry (BDL 1986, 16)

Juli 1987

27. $-29: 7$.

Günzburg: Symp. d. Deutschen Ges. f. Infektiologie (BDL 1987, 15)

Osnabrück: Seminar: Einführung i. d. Krankenhaushygiene (BDL 1987, 15) med. (BDL 1987, 15)

Düsseldorf: World Chromatography and World Spectroscopy Conference (BDL 1987, 15)

(BDL 1987. 15)

1987, 15)

Wien: Fortschritte i. d. Diagnose u. Therapie hämatologischer u. hämostaseologischer Erkrankungen (BDL 1987. 15)

Berlin: International Working Conference (BDL 1987. 15)

Erfurt: Intern. Meeting of the Danubian League against Essen: Strahlenschutz-Grundkurs f. Mediziner u. Nichtmediziner (BDL 1987, 7)

Tübingen: Behandlung radioaktiver Abfälle in Medizin und Forschung (BDL 1987, 7)

Thrombosis and Haemorrhagic Diseases (BDL 1987, 15)

. Jahresversammlung d. Schweizerr. Vereinigung $f$. Kleintiermedizin (BDL 1987, 15) u. Bayei. Urologenvereinigung (BDL 1987, 15)

Taormina-Giardini Naxos: Mediterranean Congress of Chemotherapie (BDL 1987, 15)

5ymposium f klinische Endokrinologie (BDL 1987, 15)

Martinsried: Jahrestagung d. Gesellschaft f. Genetik (BDL 1986; 15)

Washington: Int. Conference on AIDS (BDL 1987, 16)

Berlin: Arztekongreß Berlin '87 (BDL 1986, 132)

Amsterdam: European Congress on Biotechnology (BDL 1986, 120)

Franzisko: Clinical-Chemi sic and Clinical Sciences (BDL 1986, 148)

nale (BDL 1986, 132)

Tübingen: Analytische Chemie in der Toxikologie (BDL 1987, 16)

Tübingen: Einführung in die Flüssig-Szintillations-Meßtechnik (BDL 1987, 16)

Noordwijkerhout: Int Meeting on Clinical Laboratory Noordwijkerhout: Int. Meeting on Clinical Labora

Cologne: 3rd International Symposium The Influence of antibiotics on the host-parasite relationship (BDL 1987. 16) 


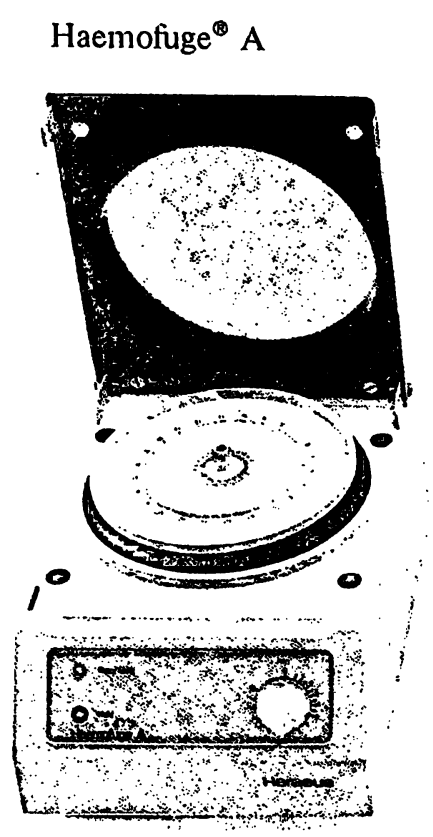

\section{Biofuge $^{\circledast} \mathrm{A}$}

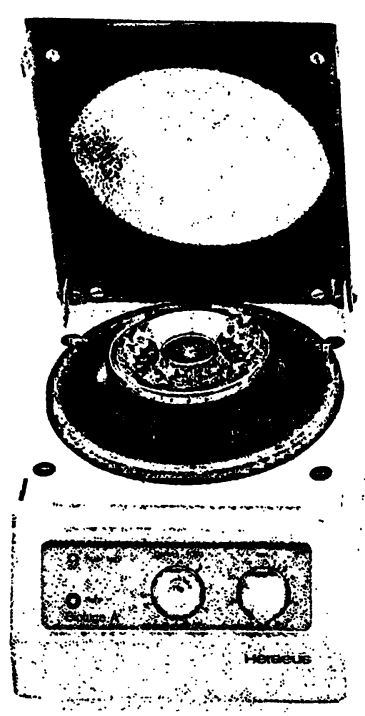

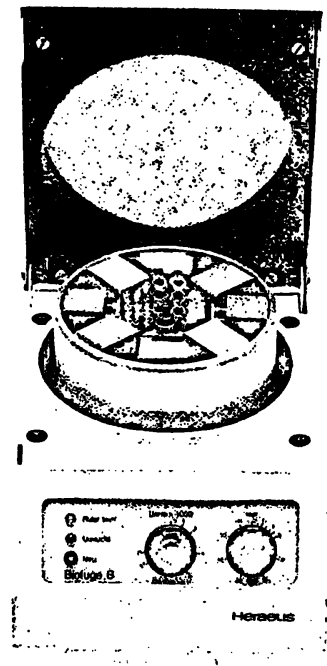

Biofuge ${ }^{\circledast}$ B
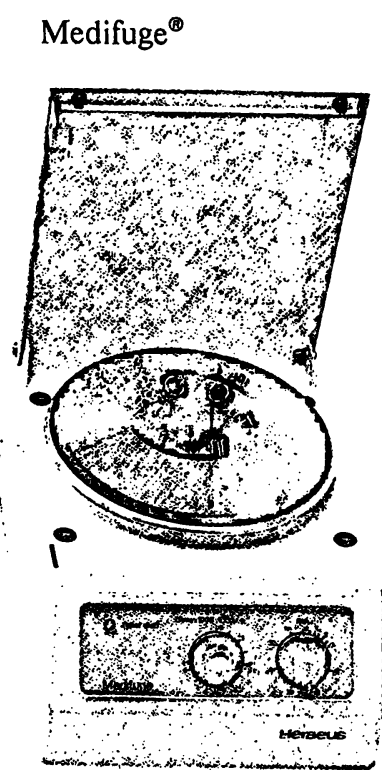

\section{Technisch gesehen}

\section{sind unsere Kleinsten die Größten. Elektronisch geregelte Kleinzentrifugen von Heraeus Sepatech}

Unsere Kleinzentrifugen haben manches, was andere nicht haben. Und umgekehrt:

Ein Anzeigeinstrument zur Kontrolle der Drehzahlen werden Sie beispielsweise vergeblich suchen Sensoren regeln sie mit einer Genauigkeit von $\leqq 1 \%$. Diese Regelgüte genügt noch Anforderungen, wie sie in Forschung und Praxis nur selten gestellt werden.

Wenn Sie bisher von unseren neuen Kleinzentrifugen noch nichts gehört haben, mag das daran liegen, daß sie die leisesten sind, die wir je gebaut haben. Ihre Geräuschentwicklung liegt je nach Modell zwischen 59 und $63 \mathrm{~dB}(\mathrm{~A})$.

Bei aller modernen Technologie erinnern einige Details noch an die gute alte Zeit: Zentrifugendeckel und Chassis sind aus Stahl und durch stabile Drehgelenke miteinander verbunden. Diese schwere, massive Bauweise gewährleistet nicht nur hohe Standfestigkeit und vibrationsfreien Lauf, sondern auch eine hohe Unempfindlichkeit gegen Unwuchten und damit eine hohe Gebrauchstüchtigkeit im täglichen Routinebetrieb.
Wenn wir Sie über alle Vorzüge, über ihre kurzen Anlauf- und Bremszeiten, ihre seidenweiche Beschleunigung, ihre einfache, durchdachte Bedienung, ihre Variabilität und ihre Sicherheitsfaktoren unterrichten sollen, so fordern Sie bitte unsere Prospekte an.

Zwei aus unserer Serie Kleinzentrifugen stellen wir Ihnen noch schnell auf der Rückseite vor.

Nennen Sie uns Ihre Wünsche.

\section{Heraeus SEPATECH}



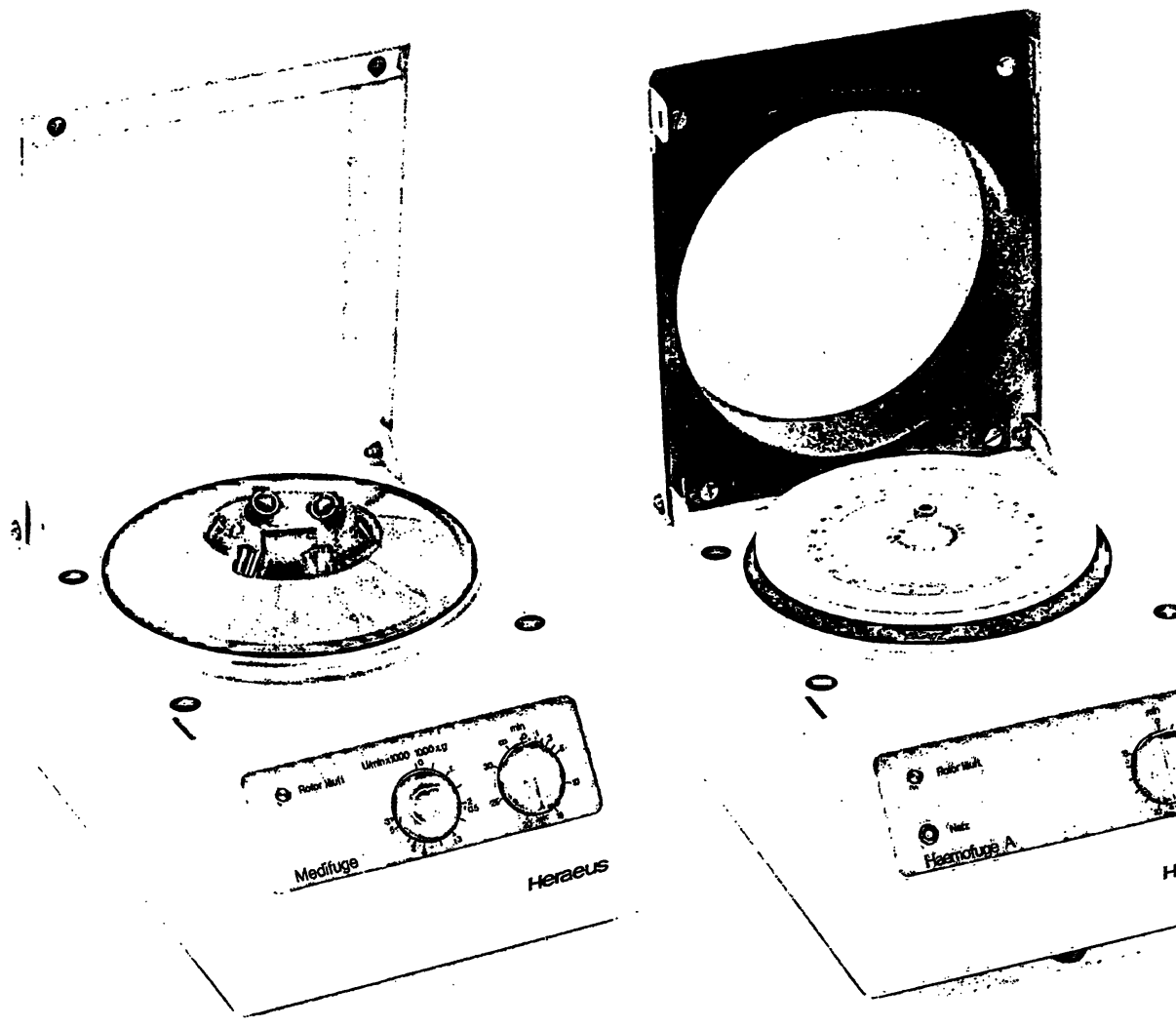

\section{Diekleine Hübsche ist für das Arztlabor. Die andere Neue ist Spezialistin für den Haematokritbereich.}

Medifuge ist der Name einer neuen Laborzentrifuge, die wir so klein, so preiswert und so gut als möglich gebaut haben, für die tägliche Routine in Arztpraxen, für Blutund Urinuntersuchungen zum Beispiel, aber auch für Untersuchungen von Suspensionen aus der organischen und anorganischen Chemie, der Botanik, Zoologie, Bakteriologie, Immunologie und Teilbereiche der biochemischen Forschung.
Als Festwinkelzentrifuge wird sie wahlweise mit einem Trommelrotor für 6 oder für 12 Röhrchen $(15 \mathrm{ml}, ø 17 \mathrm{~mm})$ verschiedener Länge bis $131 \mathrm{~mm}$ angeboten.

Die Haemofuge ${ }^{\oplus} \mathrm{A}$ wurde speziell für die Ermittlung der Haematokritwerte*) ent-

*) in Übereinstimmung mit der DIN-Vornorm 58933, einer Standardmethode zur Bestimmung des Zellpackungs-

volumens an Erythrozyten, gemessen in $\%$ am Gesamtvolumen der Blutprobe. wickelt. Sie beschleunigt den Rotor mit seinen 24 Kapillarplätzen sekundenschnell auf die Festdrehzahl von 12.000 $\mathrm{min}^{-1}$ entsprechend RZB $14.810 \times \mathrm{g}$ und bringt ihn genauso exakt nach Ablauf der eingestellten Zeit mit ihrer elektrodynamischen Bremse wieder zum Stillstand. Mit Hilfe eines aufsteckbaren Ablesetellers können die Haematokritwerte direkt in der Zentrifuge abgelesen werden. 
Die statistischen Tests liefern also kein Argument für den Ersatz des alten Assays A durch die neue Version B.

\section{Probabilistische Verfahren}

Der Einsatz probabilistischer Methoden, d.h. die Berechnung bedingter Wahrscheinlichkeiten wie diagnostische Sensitivität, Spezifität und prädiktive Werte sind inzwischen weit verbreitet. Dabei werden jedoch Diskriminationsschwellen eingesetzt, d.h. jeder Wert oberhalb der Schwelle gilt als positiv, jeder unterhalb als negativ. Bei Tests, die eine kontinuierliche Resultatskala liefern, wie es in der Klinischen Chemie fast stets der Fall ist, bedeutet diese Reduktion auf einen binären Test einen erheblichen Informationsverlust, worauf Van der Helm (8) und unser eigener Arbeitskreis in verschiedenen Publikationen (912) hingewiesen haben.

Um binäre Aussagen zu umgehen, werden heute oft ROC-Analysen eingesetzt (Übersicht bei 13), die jedoch verschiedene Nachteile haben: Die ROC-Analyse erlaubt keine Beurteilung, wie gut ein Test zwischen zwei Krank-

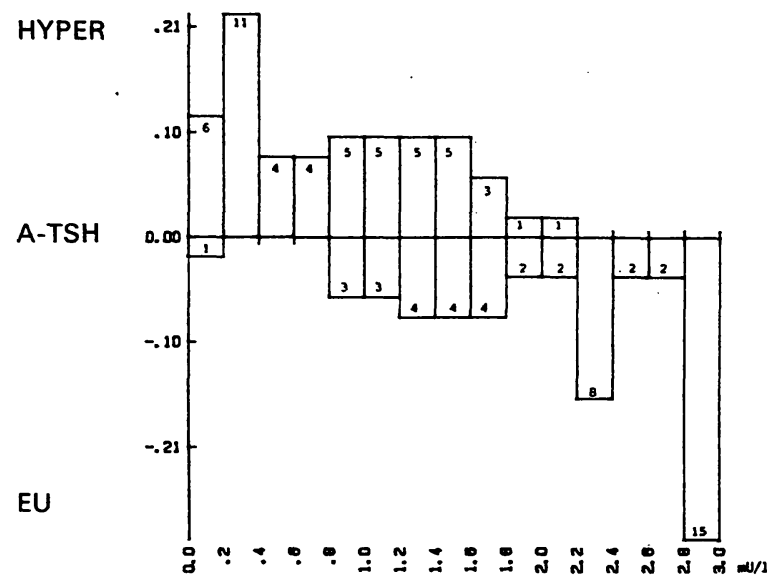

$4 a$

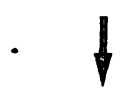

$\mathrm{RO}_{8}$

HYPER/EU

Parameter:

A-TSH

$4 b$

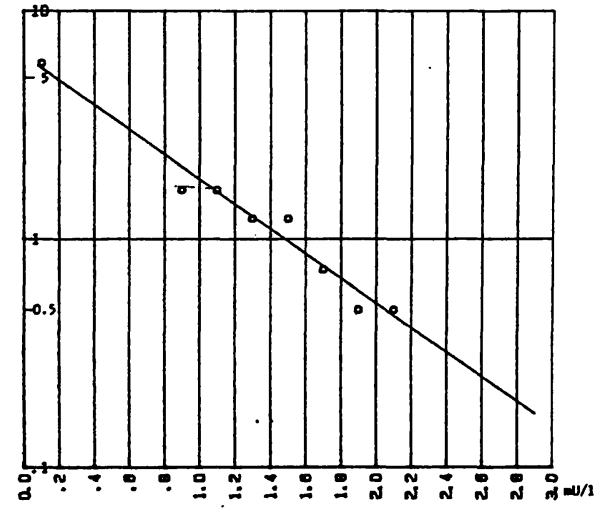

Abb. 4a: Die Daten von Abb. 1 sind für den Test $A$ als Histogramm dargestellt. Die Klassenbreite beträgt $0,2 \mathrm{mU} / \mathrm{l}$, nach oben sind die hyperthyreoten, nach unten die euthyreoten Patienten aufgetragen. Die absoluten Zahlen sind in den jeweiligen Klassen vermerkt

Abb. 4b: Die aus Abb.4a berechneten Likelihood-Quotienten sind in ein halblogarithmisches Netz übertragen und die entsprechende Ausgleichsgerade approximiert. Ihre Funktion lautet: LQGerade $=10^{-0.54}$ TSH $(A)+0.80$ heiten diskriminiert. Nur wenn sehr große Datenbasen zur Verfügung stehen, können glaubhafte ROC-Kurven konstruiert werden, die aber in jedem Fall einem smoothing" unterzogen werden müssen, um einer weiteren mathematischen Behandlung zugänglich zu sein. Schließlich repräsentieren die ROC-Kurven die individuellen Leistungscharakteristika eines Laboratoriums, d.h. bei diffizilen Tests (wie etwa Immunoassays) werden verschiedene Laboratorien oft sehr verschiedene ROC-Kurven produzieren. Schließlich erlauben die ROC-Kurven keinen Einblick in die tatsächlichen Konzentrationen der Kenngrößen, auf denen sie basieren.

Deshalb hat sich die Einführung von Likelihood-Quotienten in vielen Fällen als vorteilhaft erwiesen (14). Ein klassierter Likelihood-Quotient beziffert das Verhältnis der Kranken (exakt: des Fraktils der Kranken) zu den Gesunden (exakt: zum Fraktil der Gesunden) in einer bestimmten Klasse (der Konzentration der Kenngröße). Dabei wird vorausgesetzt, daß die beiden Kollektive gleiche Umfänge haben, z. B. daß sie jeweils auf $100 \%$ umgerechnet sind.

Abb. 4 a gibt die Hermannschen Daten für den Test $A$ wieder, wobei die Euthyreoten nach unten, die Hyperthyreoten nach oben gezeichnet sind. Die Klassenbreite beträgt

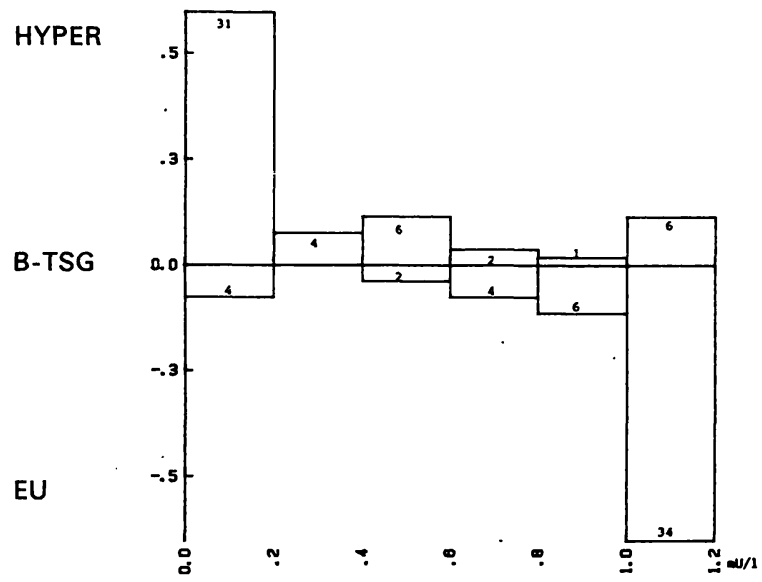

$5 a$

$\mathrm{RO}_{8}$

HYPER/EU

Parameter:

B-TSH

$5 b$

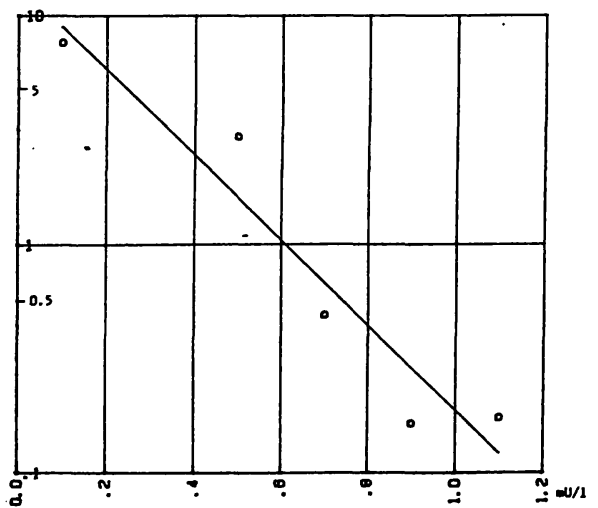

Abb. 5a: Wie Abb. 4a, jedoch für den Test $B$

Abb.5b: Wie Abb. $4 b$, jedoch für den Test B. Die Funktion der Likelihood-Geraden lautet: $L Q$-Gerade $=10^{-1,87} T T_{H}(B)+1.14$ 
$0,2 \mathrm{mU} / \mathrm{l}$, in den beiden Randklassen sind alle kleineren, resp. größeren Werte, kumuliert. Das Verhältnis der Besetzung hyper- zu euthyreot ergibt den jeweiligen klassierten Likelihood-Quotienten. Da die Kollektive den gleichen Umfang haben, ist eine "Normalisierung" nicht erforderlich.

Werden diese Quotienten in ein halblogarithmisches Netz eingetragen, so kann eine Ausgleichsgerade konstruiert werden, deren vom Rechner ermittelte Funktion in Abb. $4 \mathrm{~b}$ wiedergegeben ist. Diese Ausgleichsgerade besagt, wie das Risiko für die Annahme einer Hyperthyreose mit sinkender TSH-Konzentration steigt, resp. mit steigender TSH-Konzentration fällt. Dort, wo die Ausgleichsgerade den Likelihood-Quotient 1,0 schneidet, ist die Wahrscheinlichkeit für oder gegen Hyperthyreose gleich groß. Dies ist bei Test A etwa bei der Konzentration $1.4 \mathrm{mU} / \mathrm{I}$ der Fall, der gleiche cutt-off point wurde bereits beim numerischen Abzählen der falsch-negativen und falsch-positiven ermittelt.

Den Test B als Histogramm gibt Abb.5a wieder, wobei jedoch nur der Bereich zwischen 0,1 und 1,2 mU/I dargestellt ist. Abb. $5 \mathrm{~b}$ gibt in analoger Weise die ermittelten Likelihood-Quotienten und die daraus approximierte Ausgleichsgerade wieder.

Likelihood-Quotient 1,0 wird hier beim cut-off von $0,6 \mathrm{mU} / \mathrm{l}$ erreicht.

Die Unterschiede zwischen Test A und Test B zeigt Abb.6, wo die beiden Likelihood-Geraden zusammen in ein logarithmisches Netz eingetragen sind. Offenbar ist die Steilheit der Geraden von B wesentlich größer als von A. Ein Test, der zwei Kollektive vollständig voneinander trennt, liefert eine Likelihood-Gerade mit einer Steigung von $90^{\circ}$, beim Test ohne Trennfunktion hat die Likelihood-Gerade eine Steigung von $0^{\circ}$. Da also offenbar die Steilheit der LQ-Geraden ein Maß für die Trennfähigkeit des Tests ist, hat Test $B$ eine wesentlich höhere diagnostische Relevanz als Test $A$.

\section{Supersensitives TSH-Assay} und TRH-Test: eigene Studien

Es ergab sich nun die Frage, ob zur Erkennung einer latenten oder präklinischen Hyperthyreose oder Hypothyreose die Bestimmung der basalen TSH-Konzentration mit supersensitiven TSH-Assays ausreicht oder ob unverändert bei Zweifelsfällen der TRH-Test erforderlich ist (15) *. Diese Frage wird in der Literatur unterschiedlich beantwortet. Mehrere Autoren halten den TRH-Test für überflüssig (16-22), andere Autoren machen erhebliche Einschränkungen $(23-26)$ und schließlich wird von verschiedenen Arbeitskreisen die Möglichkeit den TRH-Test durch die Bestimmung des' basalen TSH zu ersetzen, grundsätzlich verneint $(27-29)$.

In unserem Laboratorium werden seit August 1985 probeweise verschiedene supersensitive TSH-Assays eingesetzt. Wir haben damit über $3000 \mathrm{TSH}$-Bestimmungen an Proben von spitalinternen und -externen Patienten durchgeführt, wobei wir simultan aus jeder Probe die Konzentration von Gesamtthyroxin, Gesamttrijodthyronin und TSH bestimmten. Bei internen und externen $\mathrm{Pa}$ tienten wurde in diesem Zeitraum über $850 \mathrm{mal}$ ein oraler TRH-Test durchgeführt. Dieses große Zahlenmaterial

- Ein Teil dieser Untersuchungen wurde bereits in der Schweiz. Med. Wschr. (15) publiziert.

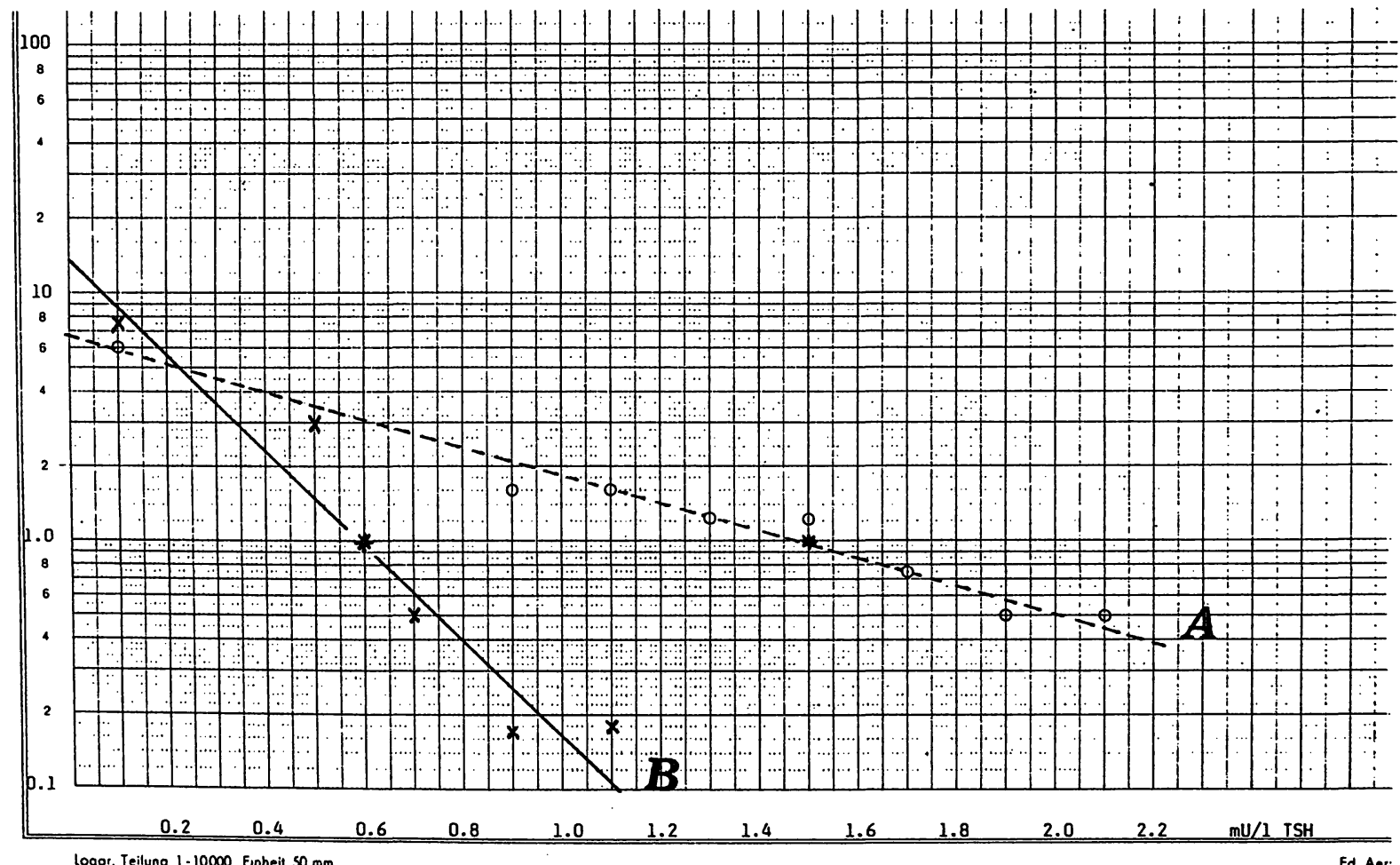

Teilung 1.10000. Einheit $50 \mathrm{~mm}$

gen. Der Likelihood-Quotient 1,0 für A, resp. B, ist mit ${ }^{*}$ Abb. 6: Die Like
gekennzeichnet 
schien geeignet, die Frage zu überprüfen, ob die basale TSH-Konzentration, bestimmt mit einem supersensitiven Assay eine zuverlässige Voraussage über den Ausfall eines TRH-Tests liefert.

\section{Referenz-Intervalle und Regressionen bei Euthyreoten}

Zunächst wurde das Referenzintervall der Kenngröße basales TSH an 100 Blutspendern im Alter zwischen 24 und 58 Jahren ermittelt. Zur TSH-Bestimmung stand uns die kommerzielle Testkombination „TSH-Irmaklon“ der Firma Henning.zur Verfügung. Die Verteilung der Konzentrationen, dargestellt als Histogramm, ist in Abb. 7 wiedergegeben. Die Verteilung ist offenbar rechtsschief und erlaubt nicht die Annahme einer Normalverteilung. Werden die Resultate jedoch logarithmiert, so erfolgt eine relativ gute Annäherung an die Normalverteilung und es kann sowohl mit parametrischen wie mit parameterfreien Verfahren das Referenzintervall definiert werden, das sich von $0,25-4,0 \mathrm{mU} / 1$ erstreckt.

Zur Charakterisierung des Schilddrüsen-Status wurde als zweiter Parameter das TSH-Inkrement nach TRH-Stimulation herangezogen. Die Selektion des Referenzkollektivs ist schwieriger, da es weder vertretbar noch praktisch durchführbar ist, gesunde Probanden einem TRH-Test zu unterziehen, einzig um Referenzwerte zu erhalten. Wir haben deshalb aus unseren Journalen solche Patienten ausgewählt, bei denen funktionelle Störungen Anlaß wa- ren eine Dysthyreose auszuschließen. Die Patienten hatten klinisch keine Anzeichen für eine Erkrankung der Schilddrüse, der Hypophyse oder des Hypothalamus. Andere schwere Erkrankungen, insbesondere der Leber und der Nieren, lagen nicht vor. Ebenso wurden Schwangere nicht in das Referenzkollektiv aufgenommen. Von allen Patienten war tT4, tT3 und der basale TSH-Spiegel bestimmt worden. Alle erhaltenen Resultate lagen in den zugehörigen Referenzintervallen.

Das Histogramm der TRH-Inkremente ist bei linearer Auftragung ebenso wie der basale TSH-Spiegel offensichtlich rechts schief (Abb. 8). Nach Logarithmierung konnte wiederum eine befriedigende Angleichung an eine Normalverteilung erreicht werden. Der Median von 8,4 stimmt fast mit dem Mittelwert überein, das Referenzintervall beträgt 3-20 $\mathrm{mU} / \mathrm{I}$.

Den Zusammenhang zwischen basalem TSH-Spiegel und TSH-Inkrement nach TRH-Stimulation bei dieser Probandengruppe zeigt Abb.9. Bei der oberen Darstellung ist auf der $x$-Achse das TSH-Inkrement, auf der $y$-Achse der basale TSH-Spiegel linear aufgetragen. Die Punktwolke läßt zwar eine Tendenz erkennen, doch ist es offenbar abwegig, eine Regressionsanalyse aufzustellen oder eine Korrelation zu errechnen.

In Abb. 9 b sind die logarithmierten Resultate eingesetzt. Nun wird der Zusammenhang beider Parameter deutlicher und es könnte eine Regressionsgerade und ein Korrelations-Koeffizient errechnet werden, doch wäre die so ge-
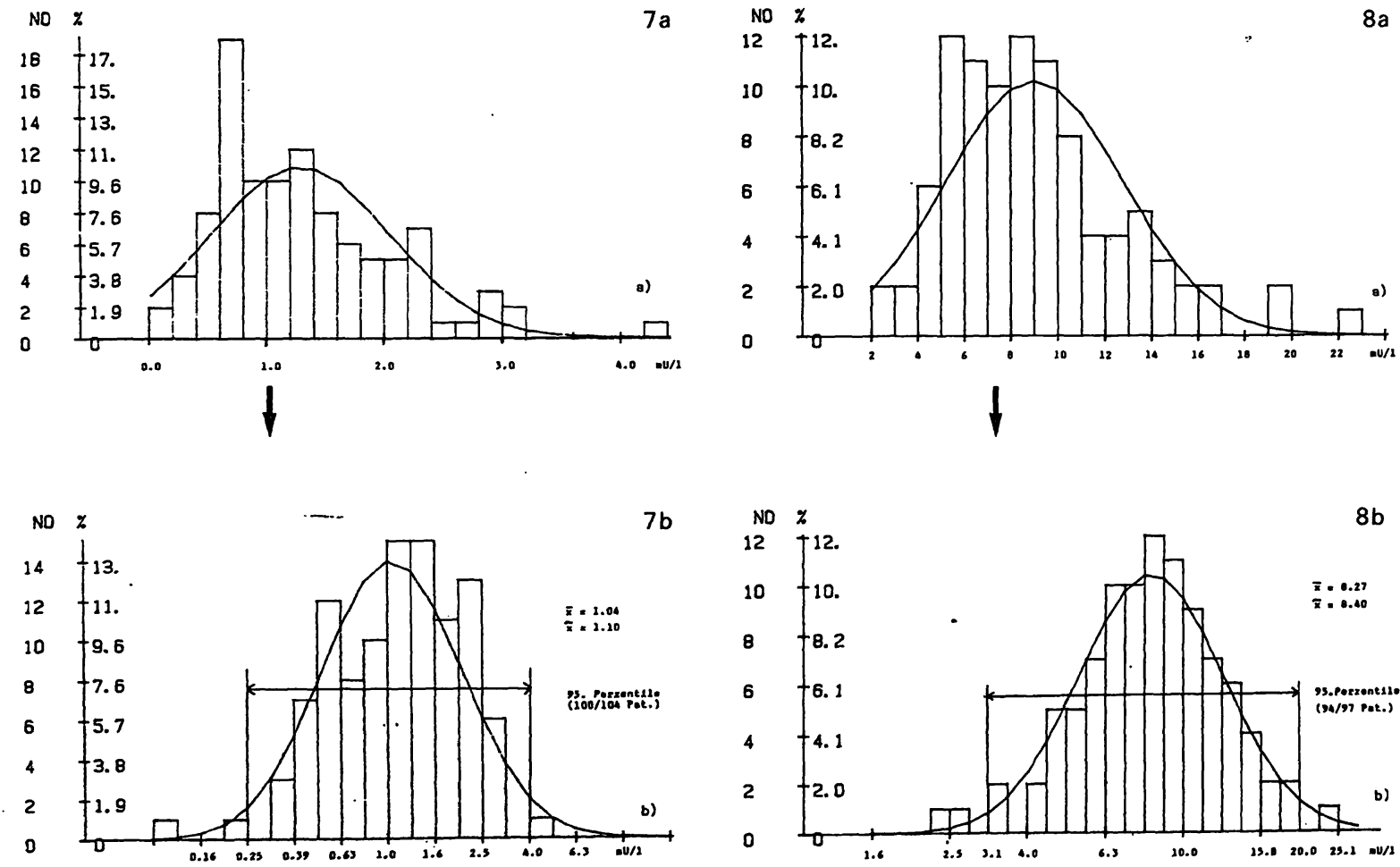

Abb. 7a: Verteilung der basalen TSH-Konzentrationen ermittelt an 104 Blutspendern. Abszisse: TSH-Konzentrationen. Ordinate: rechte Kolonne: Besetzung der Klassen, linke Kolonne: prozentualer Anteil

Abb. $7 b$ : Wie Abb. 7a, jedoch logarithmische Skalierung der $A b-$ szisse. Das Referenzintervall erstreckt sich von $0,25-4,0 \mathrm{mU} / \mathrm{I}$

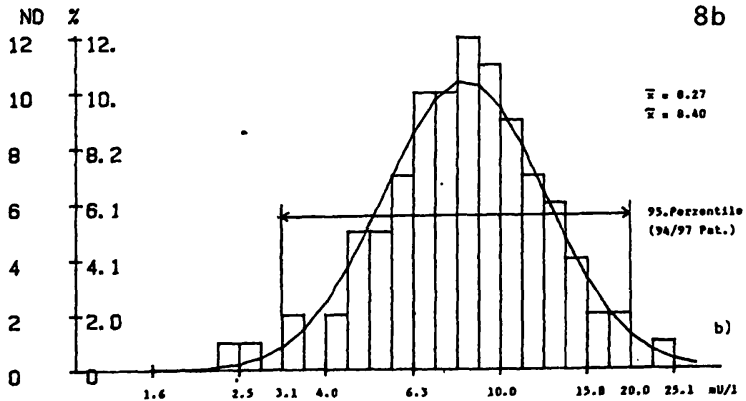

Abb. 8a: TSH-Inkrement nach TRH-Stimulation bei euthyreotem Patientenkollektiv, $n=97$. Abszisse: lineare Auftragung der TSH-Konzentration

Abb. 8b: Wie Abb. 8a, jedoch ist die Abszisse logarithmisch skaliert. Das Referenzintervall erstreckt sich (gerundet) von 3,0$20,0 \mathrm{mU} / \mathrm{I}$ 
wonnene Information für den diagnostischen Entscheidungsprozeß wertlos. Überdies handelt es sich um ein definiertes Untersuchungskollektiv euthyreoter Probanden, ohne klinischen oder labordiagnostischen Hinweis auf eine Dysthyreose. Eine Population dieser Art wird aber von den klinischen Laboratorien im allgemeinen nicht untersucht.

Dagegen wird der quantitativ größte Teil der Labordiagnostik zur Abklärung von Patienten durchgeführt, bei denen Schilddrüsenerkrankungen zumindest wahrscheinlich sind. In der Regel erhalten die beauftragten Laboratorien jedoch keine Angaben zur Klinik oder Prämedikation und sie kennen die Prävalenz von Schilddrüsenerkrankungen bei ihren Einsendern nicht.

\section{Regressionen}

\section{bei einem randomisierten Patientenkollektiv}

Um der Realität näher zu kommen, haben wir deshalb ein randomisiertes Patientenkollektiv in folgender Weise zusammengestellt:

Aus unseren Laborjournalen wurden rein zufällig entsprechend der zeitlichen Reihenfolge des Eingangs 3 Kollektive zu je 100 Proben ausgewählt. Obwohl für jede Probe die Werte von T3-, T4- und TSH-Konzentration vorlagen

$9 a$
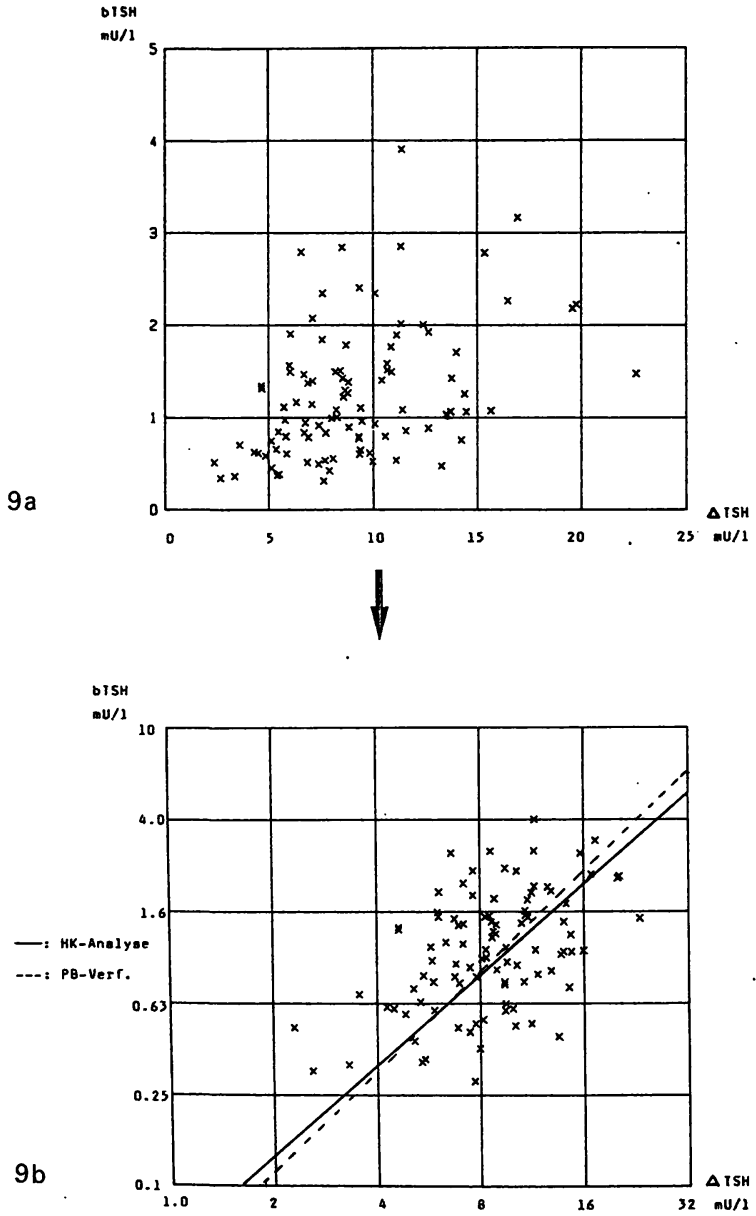

Abb. 9a: Zusammenhang zwischen TSH-Inkrement und basalem TSH-Spiegel. Bei linearer Auftragung beider Kenngrößen der Patienten von $A b b .8$

Abb. 9b: Wie Abb. 9a, jedoch bei logarithmischer Auftragung und z.T. auch klinische Angaben verfügbar waren, wurden die drei Kollektive ausschließlich nach dem ermittelten TSH-Inkrement gewählt:

- Kollektiv A (REGUL) mit regulärer Antwort auf TRHStimulation repräsentiert Patienten, deren TSH-Inkrement zwischen 3 und $20 \mathrm{mU} / \mathrm{l}$ lag.

- Kollektiv B (SUPRA) umfaßt Patienten, deren TSHInkrement $>20 \mathrm{mU} / \mathrm{l}$ war und

- Kollektiv C (INFRA) umfaßt Patienten mit einem TSH-Inkrement von $<3 \mathrm{mU} / \mathrm{l}$.

Werden die Kollektive A, B und $C$ in ein KoordinatenNetz eingetragen (Abb.10), so streuen sie so stark, daß eine Korrelation kaum erkennbar ist. In der Abbildung sind Wertpaare über den Skalengrenzen nicht dargestellt. Immerhin ist von den drei Kollektiven folgendes festzuhalten: Kollektiv A mit regulärem TRH-Response liegt überwiegend im Referenzintervall der basalen TSH-Konzentration, doch gibt es einzelne Fälle, die darunter und einige, die darüber liegen. Kollektiv $C$ mit eingeschränktem TSH-Response liegt zum größten Teil unterhalb, zu einem erheblichen Teil aber auch innerhalb und schließlich sogar oberhalb des Referenzintervalls der basalen TSH-Konzentration. Schließlich liegt Kollektiv B mit überschießender TSH-Antwort zum größten Teil inner-
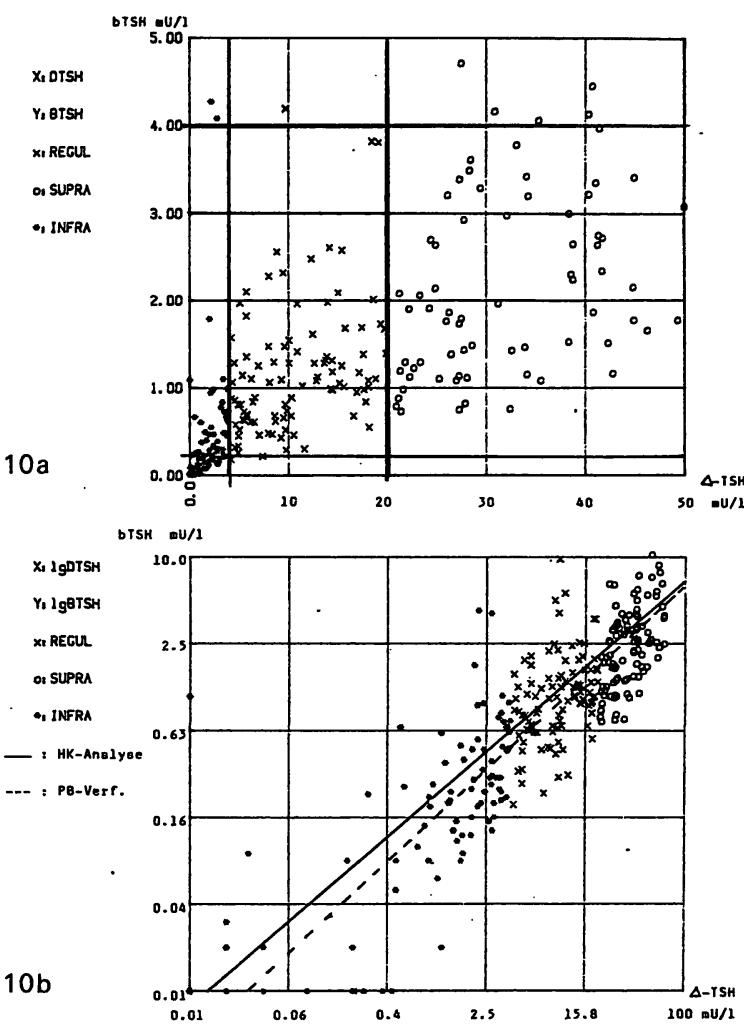

Abb. 10a: Zusammenhang zwischen TSH-Inkrement und basalem TSH-Spiegel bei linearer Auftragung beider Kenngrößen bei verschiedenen Patientenkollektiven. $x=$ REGUL: Patienten mit regulärem A-TSH (3-20 mU/I), $\mathrm{O}=$ SUPRA: Patienten mit überschießendem A-TSH (>20 mU/I), * = INFRA: Patienten mit eingeschränktem $\Delta-T S H(<3,0 \mathrm{mU} / \mathrm{I})$. Die Referenzintervalle sind durch vertikale Linien gekennzeichnet

Abb. 10b: Wie Abb. 10a, jedoch sind beide Achsen logarithmisch skaliert. Zusätzlich wurde die Ausgleichsgerade der Hauptkomponęinten-Analyse und der Passing-Bablok-Schätzung eingetragen 
- halb, zu einem kleineren Teil oberhalb des Referenzintervalls des basalen TSH-Spiegels. Auch bei dieser Population wird der Zusammenhang zwischen dem TSH-Inkrement und dem basalen TSH-Spiegel visuell deutlicher, wenn die Logarithmen beider Kenngrößen dargestellt werden (Abb.10b). Durch diese formale Verbesserung der Anschaulichkeit wird natürlich keine Änderung der biologischen Abhängigkeit erreicht. Wegen des lockeren Zusammenhangs zwischen beiden Parametern ist für die praktische Laboratoriumsdiagnostik eine Abschätzung des TSH-Inkrements aus dem basalen TSH-Spiegel offenbar unzulässig. Wahrscheinlichkeitstheoretische Überlegungen machen dies noch deutlicher.

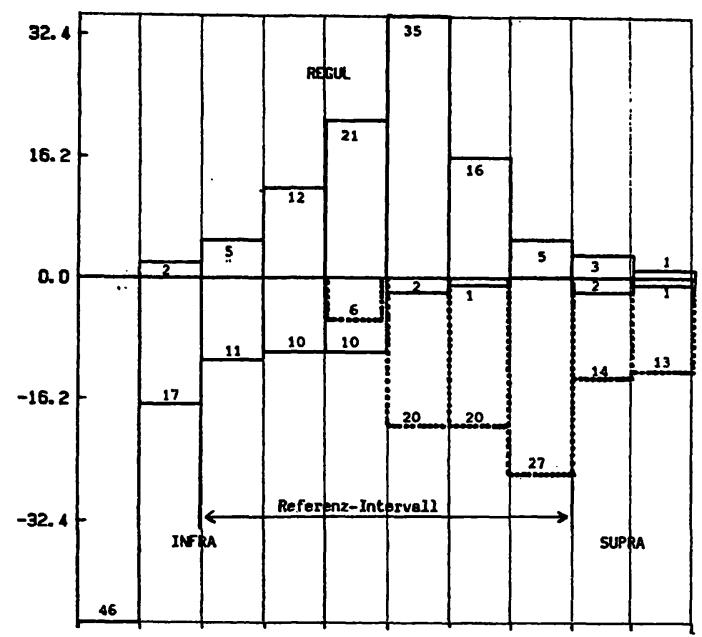

${ }_{\text {RQ }} Q_{\text {INFAA }}=10^{-2.53} 1 \mathrm{~g} \mathrm{BTSH-0.81}$

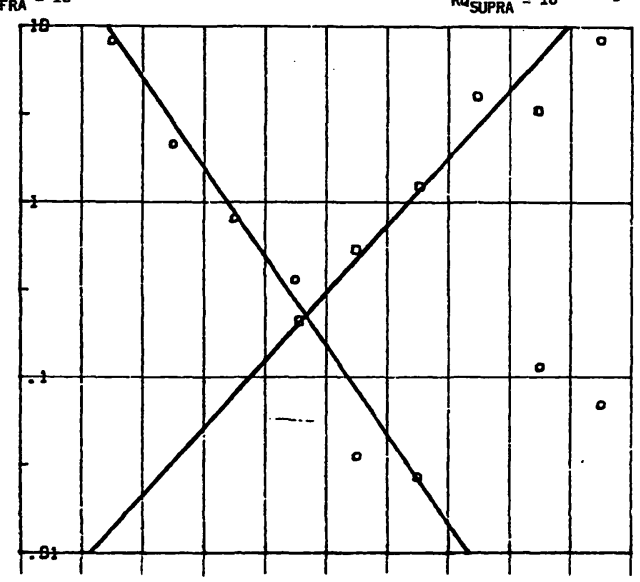

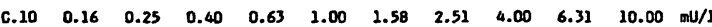

Abb. 11 a: Auf der $x$-Achse sind die basalen TSH-Konzentrationen 0,1-10 mU/l logarithmisch in 10 Klassen aufgeteilt, nach oben das Kollektiv REGUL, nach unten das Kollektiv INFRA (durchgezogen) und das Kollektiv SUPRA (punktiert). In den Randklassen sind alle Patienten summiert, die außerhalb der Skala liegen. In jeder Klasse ist die absolute Zahl der Patienten angegeben

Abb. 11 b: Für die Klassen 1-10 wurden die Likelihood-Quotienten INFRA/REGUL und SUPRA/REGUL errechnet. Die so erhaltenen Punkte sind in ein logarithmisches Netz eingetragen und die korrespondierenden LQ-Geraden approximiert (näheres siehe Text)

\section{Probabilistische Betrachtungen}

In Abb.11 sind die 3 Kollektive gemeinsam als Histogramm aufgetragen, wobei Kollektiv A nach oben, Kollektiv $B$ und $C$ nach unten gerichtet sind. Die basale TSHKonzentration ist logarithmisch auf der Abszisse skaliert. Die Besetzung der Klassen ergibt sich aus der Ordinate, die absoluten Zahlen sind in den einzelnen Klassen eingetragen. Von den 10 Klassen werden 9 vom Kollektiv $A$ überdeckt, nur die unterste Klasse mit einem basalen TSH-Spiegel von $<0,16 \mathrm{mU} / \mathrm{I}$ ist ausschließlich von einem Teil des Kollektivs $C$ belegt. Dieses Kollektiv überdeckt aber das gesamte Referenzintervall und geht sogar darüber hinaus. Kollektiv $B$ hat seinen Schwerpunkt im oberen Teil des Referenzintervalls, nur $1 / 4$ der Patienten überschreitet es.

Das Verhältnis von Kollektiv $\mathrm{C}$ zu den beiden anderen kann für die Klassen 2-7 berechnet werden, das Verhältnis von Kollektiv B zur Summe der Kollektive A und C für die Klassen 5-10. Werden die so ermittelten LikelihoodQuotienten in ein logarithmisches Netz eingetragen, dessen Abszisse der oberen Abbildung entspricht und dessen Ordinate logarithmisch skaliert ist, so lassen sich die Likelihood-Quotienten für das Kollektiv $C$ zu einer von links nach rechts abfallenden Geraden, für das Kollektiv B von einer links nach rechts ansteigenden Geraden approximieren. Die entsprechenden Funktionen erlauben die Berechnung der Mutmaßlichkeit für die Zugehörigkeit zu Kollektiv C mit sinkendem, bzw. zu Kollektiv B mit steigendem basalem TSH-Spiegel. Dort, wo die Geraden den Ordinatenwert 1,0 schneiden, verhält sich die jeweilige Mutmaßlichkeit wie 1:1. Demnach liegt diese 1:1-Zugehörigkeitschance für Kollektiv $\mathrm{C}$ bei $0,48 \mathrm{mU} / \mathrm{l}$, für Kollektiv B bei 1,65 mU/I.

Zur besseren Anschaulichkeit können die LikelihoodQuotienten in Wahrscheinlichkeiten umgerechnet wer-

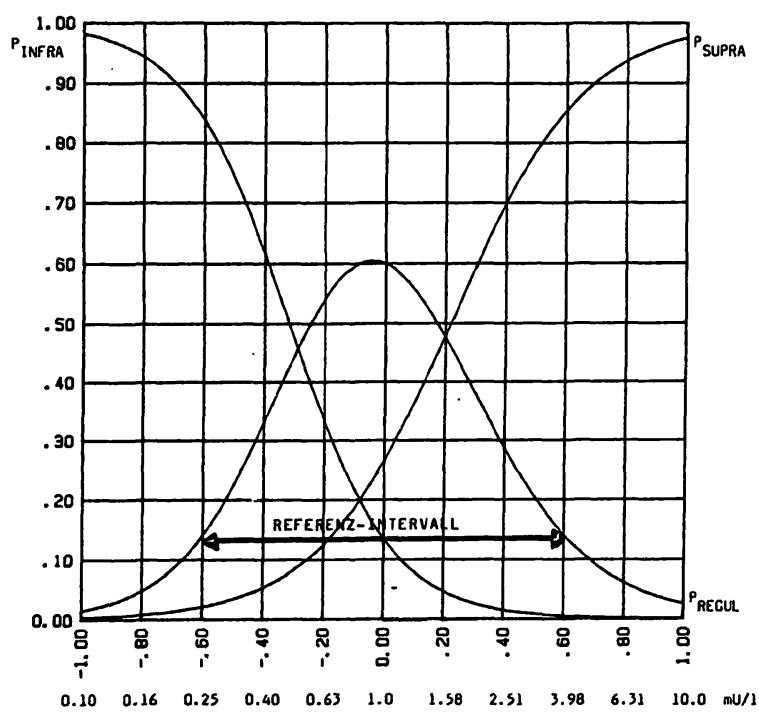

Abb. 12: Die Likelihood-Quotienten aus $A b b .11 b$ wurden in Wahrscheinlichkeiten transformiert. Die Auftragung der $x$-Achse entspricht $A b b .11$, die $y$-Achse stellt die Wahrscheinlichkeiten dar. Die Abbildung zeigt, wie die Wahrscheinlichkeit für die Zugehörigkeit zum Kollektiv INFRA mit steigendem basalem TSH sinkt, während die Wahrscheinlichkeit für die Zugehörigkeit zum Kollektiv SUPRA steigt. Die Differenz 1-(SUPRA + INFRA) entspricht der Wahrscheinlichkeit für die Zugehörigkeit zum Kollektiv REGUL. 
den. In Abb. 12 sind auf der Abszisse in analoger Weise wiederum die Klassen eingetragen, auf der Ordinate die linearen Wahrscheinlichkeiten für die Zugehörigkeiten zu den Kollektiven $C, B$ und $A$. Man erkennt daraus, daß nur im Bereich zwischen 0,5 und 1,6 mU/I die Wahrscheinlichkeit für die Zugehörigkeit zum Kollektiv A größer ist als zum Kollektiv C, bzw. B. Beim Median von etwa $1.0 \mathrm{mU} / \mathrm{l}$ ist die Wahrscheinlichkeit der Zugehörigkeit zum Kollektiv A am größten, beträgt jedoch nur etwa $60 \%$. Das Referenzintervall, das aus der Blutspenderpopulation geschätzt wurde, ist offensichtlich nach beiden Seiten breiter als jenes Intervall, das sich aus dem Vergleich der drei Patientenkollektive ergibt.

Diese graphische Darstellung der Wahrscheinlichkeiten für die Zugehörigkeit zum Kollektiv A, B oder $C$ gilt aber nur für unser Laboratorium. Nach dem Bayes'-Theorem sind prädiktive Werte von der Prävalenz abhängig (Übers. bei 16). Die Wahrscheinlichkeit für eingeschränkte oder erhöhte TSH-Antwort auf TRH-Stimulation basiert also auf den Prävalenzen, die in unserem Labor zur Zeit gelten: von 842 TRH-Tests fanden wir bei 502 Proben eine reguläre TSH-Antwort, bei 175 eine eingeschränkte und bei 165 eine überschießende. In unserem Material verhält sich also $C$ zu $A$ zu $B$ etwa wie $1: 3: 1$. In anderen Laboratorien mag dieses Verhältnis wesentlich anders sein und entsprechend andere Voraussagen würden sich ergeben.

\section{Schlußfolgerungen}

Die vorliegenden Ergebnisse zeigen, daß ein Screening der Schilddrüsenfunktion allein durch die Bestimmung des basalen TSH-Spiegels nur dann angezeigt ist, wenn eine begründete ärztliche Indikation vorliegt. (Eine Ausnahme bildet das Screening der Neugeborenen auf eine Schilddrüsenaplasie.) Ohne zusätzliche klinische Information ist ein normaler oder abnormaler basaler TSHSpiegel für sich allein nicht interpretierbar, auch wenn er mit einem "supersensitiven Assay" bestimmt wurde. Speziell die präklinische Hyperthyreose wird dadurch nicht sicher erkannt. Auch muß betont werden, daß sich das TSH-Inkrement (nach TRH-Stimulation) nicht mit ausreichender Wahrscheinlichkeit aus dem basalen TSHWert voraussagen läßt. Generell zeigt dieses Beispiel, daß ein Referenzintervall, festgelegt an "Nicht-Kranken“, oft keine zuverlässigen Entscheidungskriterien zur Erkennung von „Kranken" liefert.

Anschrift des Verfassers:

Prof. Dr. Dr. Herbert Keller

Kantonsspital

$\mathrm{CH}-9007$ St. Gallen
Schriftum:

1. WOOD.W. G., WALLER. D. HANTKE. U.: An evaluation of six solid phase thyrotropin (TSH) kits. J. Clin. Chem. Clin. Biochem. 23, 461-471 (1985).

2. HERMANN G A SUGIURA H T KRUMM R P. Comparison of thyrotropin assays by relative operating characteristic analysis. Arch. Pathol. Lab. Med. 110, $21-$ 25 (1986)

3. PASSING, H., BABLOK, W.: Comparison of several regression procedures for method comparison studies and determination of sample sizes. J. Clin. Chem. Clin. Biochem. 22, 431-445 (1984).

4. AVERDUNK, R, BORNER, K.: Korrelation der Thromboplastinzeiten bei Dicumarolbehandelten Patienten unter Verwendung verschiedener Thrombokinase-Präparate. Z. Klin. Chem. 8. 263-268 (1970).

6. FELDMANN, U., SCHNEIDER, B., KLINKERS, H., HAECKEL., R.: A multivariate approach for the biometric comparison of analytical methods in clinical chemistry. J. Clin. Chem. Clin. Blochem. 19, 121-127 (1981).

6. LORENZ, R. J.: Grundbegriffe der Biometrie. G. Fischer Verlag. Stuttgan 1984

7. HARTZ, A. J.: Overlap-Index. Arch. Pathol, Lab. Med. 108, 65-67 (1984).

8. VAN DER HELM. J. J., HISCHE, E. A. H.: Application of Bayes theorem to results of quantitative clinical chemical determination. Clin. Chem. 25, 985-988 (1979). 9. KELLER, H., GESSNER, U.: Auswahl und Interpretation diagnostischer Parameter. Internist 21, 173-180 (1980).

10. KELLER, H., GESSNER, U.: Bayes theorem and quantitative clinical chemical determination. Clin. Chem. 27, 1959-1960 (1981).

11. KELLER, H.: The likelihood quotient line, a tool for assessment of diagnostic validity of clinical chemical tests. J. Clin. Chem. Clin. Biochem. 19. 211-212 (1981). 12. KELLER, H., GESSNER, U.: Assessing the risk of disease with multiple lab variables. Diagnostic medicine 6, 50-60 (1983).

13. McNEIL, B. J., HANLEY, J. A.: Statistical approaches to the analysis of receiver operating characteristic (ROC) curves. Med. Decis. Making 4, 137-150 (1984).

14. KELLER, H.: Klinische Chemie: Kriterien zur Beurteilung diagnostischer Tests. Verlag Dische. Ges. Inn. Med. 91, 83-94 (1985).

15. KELLER, H.: Ersetzt die Bestimmung der basalen TSH-Konzentration den TRH Test? Schweiz. Med. Wschr. 116, 1009-1015 (1986).

16. KERR, D. J., ALEXANDER, W. D.: Is the TRH test usually unnecessary? Lancet 1984/II, 1161-1162.

17. BERNUTZ, C., HORN, K., KONIG, A., PICKARDT, C. R.: Advantages of sensitive assays for thyrotropin in the diagnosis of thyroid disorders. J. Clin. Chem. Clin. Biochem. 23, 851-856 (1985).

18. BERNUTZ, C., KEWENIG, M., HORN, K., PICKARDT, C. R.: Detection of thyroid disorders by use of basal thyrotropin values determined with an optimized "sandwich" enzyme immunoassay. Clin. Chem. 31, 289-292 (1985).

19. JOSEPH, K.: Erstdiagnostik und Verlaufskontrollen bei Schilddrüsenfunktionsstörungen mit der immunradiometrischen TSH-Bestimmung. NucComp. 16, 240-254 (1985)

20. PFANNENSTIEL, P.: Significance of supersensitive TSH-determinations and its relationship to free T4 and free T3. NucComp. 16, 396-398 (1985).

21. SETH, J., KELLETT, H. A., CALDWELL, G., SWEETING, V. M., BECKETT, G. J. GOW, S. M., TOFT, A. D.: A sensitive immunoradiometric assay for serum thyroid stimulating hormone: a replacement for the thyrotropin releasing hormone test. Brit. Med. J. 289, 1334-1336 (1984).

22. WEHMANN, R. F., HALLE, A. B.: Clinical utility of thyrotropin assays: the responsibility of the clinical chemist. Clin. Chem. 31,329 (1985).

23. SCRIBA, P. C. et al.: Schilddrüsenfunktionsdiagnostik und die Diagnose von Schilddrüsenkrankheiten (I). Int. Welt 50-57 (1985).

24. WOOD, W. G., WALLER, D., HANTKE, U.: An evaluation of six solidphase thyrotropin (TSH) kits. J. Clin. Chem. Clin. Biochem. 23, 461-471 (1985).

25. ALLEN, K. R., WATSON, D.: Thyrotropin as the initial screening test for thyroid disease. Clin. Chem. 30, 502-503 (1984).

26. MAHLSTEDT, J., HOTZE, A.: Erste Erfahrungen mit einem ultrasensitiven immunradiometrischen TSH-Assay. NucComp. 16, 72-76 (1985)

27. KIRKEGAARD, C., BREGENGARD, C.: Is the TRH test necessary? Lancet 1985/I 222.

28. KLINGLER, W., BALL, P.: Die Bestimmung des Thyreotropin (TSH) im Serum mit einer sensitiven immunoradiometrischen Methode. Ärztl. Lab. 31, 219-223 (1985). 29. RODRIQUEZ-ESPINOSA, J., ORDONEZ-LLANOS, J., MORA-BRUGUES, J. LOPEZ-CALULL, C., CORTES-RIUS, M.: Sensitive immunoradiometric assay (IRMA) for serum thyrotropin may be insufficient to make the thyrotropin-releasing-factor test unnecessary. Clin. Chem. 31, 1081-1082 (1985) 